NBER WORKING PAPER SERIES

\title{
DECENTRALIZED EMPLOYMENT AND THE TRANSFORMATION OF THE AMERICAN CITY
}

\author{
Edward L. Glaeser \\ Matthew E. Kahn \\ Working Paper 8117 \\ http://www.nber.org/papers/w8117
}

\author{
NATIONAL BUREAU OF ECONOMIC RESEARCH \\ 1050 Massachusetts Avenue \\ Cambridge, MA 02138 \\ February 2001
}

Glaeser and Kahn both thank the National Science Foundation for financial support. Jesse Shapiro and Meghan McNally provided extremely helpful research assistance. We thank Richard Arnott, Chris Mayer, Ken Small and conference participants for useful comments. The views expressed herein are those of the authors and not necessarily those of the National Bureau of Economic Research.

(C) 2001 by Edward L. Glaeser and Matthew E. Kahn. All rights reserved. Short sections of text, not to exceed two paragraphs, may be quoted without explicit permission provided that full credit, including (C) notice, is given to the source. 
Decentralized Employment and the Transformation of the American City Edward L. Glaeser and Matthew E. Kahn

NBER Working Paper No. 8117

February 2001

\begin{abstract}
This paper examines the decentralization of employment using zip code data on employment by industry. Most American cities are decentralized-on average less than 16 percent of employment in metropolitan areas is within a three mile radius of the city center. In decentralized cities, the classic stylized facts of urban economics (i.e. prices fall with distance to the city center, commute times rise with distance and poverty falls with distance) no longer hold. Decentralization is most common in manufacturing and least common in services. The human capital level of an industry predicts its centralization, but the dominant factor explaining decentralization is the residential preferences of workers. Political borders also impact employment density which suggests that local government policies significantly influence the location of industry.
\end{abstract}

Edward L. Glaeser

Harvard University Brookings Institution and NBER
Matthew E. Kahn

Tufts University 


\section{Introduction}

In 1899, Adna Weber began his masterpiece on urban growth in the $19^{\text {th }}$ century by writing that, "the most remarkable social phenomenon of the present century is the concentration of population in cities." One hundred years later, the evolution of cities is still among the most interesting and important of social phenomena. America is in the midst of an urban transformation so profound that it is changing completely the spatial organization of economic activity. In 1900, urban America lived and worked in high density communities that allowed most people to travel with their own feet. By the middle of the century, the stereotypical city still had a dense urban core where people worked, but the majority of urban residents lived in suburban communities and commuted by cars. At the dawn of the $21^{\text {st }}$ century, jobs have followed workers and America is increasingly a national of moderate density, edge-cities (using Joel Garreau's, 1992, terminology).

The data document a truly massive change in the American city. In 1940, only one of the ten largest cities in the U.S. had a population density below 10,000 people per square mile (Los Angeles). In 1990, population density levels are below 7,500 people per square mile in seven out of the ten largest cities. Cities of the past were built at higher densities because, after all, in 1920, cars were rare. ${ }^{1}$ Even in 1960, only 64 percent of the population drove to work. In 1990, 86.5 percent of Americans drive to work. In 1940, the overwhelming number of urban jobs appear to have been close to the city center. In 1996, in the average metropolitan area only 16 percent of jobs are within 3 miles of the central business district. The dense, walking city of the $19^{\text {th }}$ century has been replaced by the medium density, driving city of today.

This decentralization of the American city proceeded in two waves. First, people moved their residences to the suburbs. This flight of urban workers to the suburbs started in the late $19^{\text {th }}$ century with the first commuter trains and streetcars (Warner, 1975). The

\footnotetext{
${ }^{1}$ According to the 1995 Highway Statistics Summary, US Department of Transportation, in 1920 the ratio of cars to households was .33.
} 
introduction of the mass produced automobile democratized the suburbs and led to a massive reshaping of the urban landscape. But as late as 1960, 63 percent of jobs were in the central city and 51 percent of metropolitan area population lived in the suburbs (Mieszkowski and Mills 1993). People lived at low densities, but they worked at high densities.

In 2000, people both live and work in the suburbs. This paper is focused on the second wave of urban sprawl: the decentralization of employment. First, we document basic facts about the decentralization of employment. In 1996, we find that across the United States, the average metropolitan area is remarkably decentralized. ${ }^{2}$ The median employee works eight miles from the city center and the median resident lives nine miles from the city center. New York City is apparently the only major metropolitan area that really has a monocentric employment structure (the median employee in New York works only three miles from the city center). Chicago, for example, is almost as decentralized as Los Angeles. Across cities, we show that the correlation between city age and decentralization is surprisingly weak, and that regional patterns are less extreme than is often thought. The Northeast and the Midwest have many areas that are just as decentralized as the South and the West.

We use cross-industry variation to try and understand what drives the suburbanization of industry. ${ }^{3}$ We examine four reasons why firms choose particular locations: 1) land costs, 2) access to ideas, 3) access to workers, and 4) transport cost savings for inputs and outputs. This framework re-emphasizes the fact that cities exist to save transport costs for goods, for people, and for ideas (Glaeser 1998).

\footnotetext{
${ }^{2}$ There is no generally accepted, rigorous definition of decentralization. We would like to compare these figures against some existing historical, or international norm. However, our zip code level data is not available prior to 1994, and no international equivalents exist (to our knowledge). We take 100 percent centralization as a benchmark, and feel quite comfortable thinking of metropolitan areas that have less than one-quarter of their employment within three miles of their central business district as being decentralized.

${ }^{3}$ Carlino (1985) using a county level data set concludes that manufacturing suburbanization has led to the decentralization of people and non-manufacturing industries. Cooke (1983) concludes that both agglomeration economies and economizing on transportation costs help explain manufacturing suburbanization in Cincinnati.
} 
We use a number of (admittedly weak) proxies for land use to test whether industries that use more land tend to suburbanize. Industries with higher electricity usage (a possible proxy for land use) are more likely to decentralize. Manufacturing industries, which are generally more land intensive, are also more likely to decentralize.

Our best test of the importance of idea flows in dense urban centers is to examine whether skill-intensive industries are less likely to decentralize. Indeed, the relative centralization of skilled industries appears to be a fairly robust phenomenon. Industries with more skilled workers- which we see as a measure of the intellectual intensity of the industry- and industries where workers use computers- also a proxy for intellectual intensity- are more likely to locate in the city center. This finding is particularly surprising since high human capital workers are more likely to suburbanize, and this would naturally induce high human capital industries to suburbanize as well. ${ }^{4}$

One piece of evidence, which suggests that firms suburbanize to get access to workers is that industries, whose workers are more likely to suburbanize are more likely to suburbanize their employment. To address one endogeneity problem with this resultperhaps firms that are more likely to suburbanize for exogenous reasons choose to hire more suburbanized workers- we use cross-city, cross-industry data. In particular, we ask whether industries whose national employment patterns suggest that they are particularly likely to suburbanize in a given city do indeed suburbanize more than the norm of either that city or their industry. This appears to be the case. We also find, across metropolitan areas, that places that were more suburbanized in population in 1969, had faster decentralization of employment between 1969 and 1997. Jobs have followed people.

Our final goal was to investigate the role of government in the location of employment. Following the methodology of Holmes (1998), and our own prior work on cities (Glaeser, Kahn and Rappaport, 2000), we look at whether there are political boundary effects on employment, holding distance from the city center constant. While significant boundary

\footnotetext{
${ }^{4}$ The fact that firms with workers in the suburbs to locate in the suburbs is driven by industries with older workers and workers with families, not industries with high human capital workers.
} 
effects show up in most metropolitan areas, they are sometimes positive and sometimes negative. There appear to be two patterns of government-employment relationships across U.S. MSAs. In some cities, there is a pro-central city bias which appears to come about because relatively rich suburbs fight to stop employment growth in their areas. On the other hand, some central cities tax businesses so much that they drive them away. We have attempted to create a categorization across metropolitan areas of these different types of cities.

This paper has two main conclusions about the decentralization of industry in America. First, worker residential preferences appear to be extremely important. If spatial patterns in the past were dictated mainly by the productivity advantages of particular locales for firms, spatial patterns now seem to be driven as much by consumption advantages experienced by workers. Second, the primary force fighting decentralization seems to be the urban advantage in speeding the flow of ideas. Our proxies for idea-intensiveness are the most reliable predictors of centralization.

Section II presents basic facts on the level of decentralization of population within the U.S. Section III presents a theoretical framework for thinking about the causes of heterogeneity in decentralization across industries and metropolitan areas. Section IV tests the basic implications of that framework.

\section{Basic Facts}

Before discussing our analytical framework, we begin with a set of stylized facts about the decentralization of urban jobs. We have two sources of data. The first source is county level data on population and employment by major industries from the Department of Commerce Regional Economic Information System (REIS) CD-ROM. This data is useful primarily because it can be used to provide us with a time series on the decentralization of employment. Our second source of data contains employment information at the zip code level for every metropolitan area zip code in the United States in 1996. Most of our empirical work will rely on this zip code level information. 


\section{Data Description}

The U.S. Department of Commerce's Zip Code Business Patterns 1996 data provides firm counts by firm employment size by four digit SIC level by zip code. ${ }^{5}$ The Zip Code Business Patterns data are extracted from the Standard Statistical Establishments List, a file of all known single and multi-establishment companies maintained and updated by the Bureau of the Census. The data set identifies 10,556 zip codes within 335 metropolitan areas. There are 454 three digit SIC industries identified (by the 1987 classifications). Most of the nation's economic activity is covered in this series. Data are excluded for self-employed persons, domestic service workers, railroad employees, agricultural production workers, and most government employees.

We locate each zip code to determine whether it lies within a MSA and what is its distance from the MSA's Central Business District (CBD). The locations of the CBDs are given by the 1982 Economic Censuses Geographic Reference Manual, which identifies the CBDs by tract number. The data source for each zip code's distance from the CBD is found in Chua (1999). ${ }^{6}$ While zip codes are not ideal geography (due to their unusual shapes), they do offer the opportunity to study within MSA variation in economic activity.

\section{Basic Facts}

Figure 1 shows the cumulative distribution of population and employment by distance from the central business district across the United States as a whole. The figure illustrates the fact that 25 percent of employees work within three miles of their

\footnotetext{
${ }^{5}$ Taking the midpoint of employment within each size category and using an employment level of 1200 for firms that are top coded at 1000, we calculate a zip code's total employment by SIC code. We aggregate industry employment up to the three digit SIC level.

${ }^{6}$ The GIS (geographic information systems) software package ArcView is used to calculate the distance from the centroid of each ZIP code to the centroid of the corresponding CBD. ZIP code centroid data are from the ESRI Data and Maps CD-ROM (Environmental Systems Research Institute, Inc., 1999) and the MARBLE geocorrelation engine (www.ciesin.org).
} 
metropolitan area center and 20 percent of people live within three miles of the city center.

Figure 1 makes two points. First, most metropolitan employees work more than fives miles from the city center. On average, the monocentric model is a fairly poor approximation for the reality of American cities. Second, while employment is slightly more centralized than population, the difference is not that large. Basically, population and employment track each other well.

Figure 2 examines the employment decentralization for the three largest metropolitan areas: New York City, Los Angeles and Chicago. New York City is one city that truly does fit the monocentric model. A full 50 percent of New York's employment works within three miles of the city center (Wall Street). ${ }^{7}$ Several factors help to explain the centralization of New York City. First, New York's geography makes sprawl particularly difficult. The Wall Street area is surrounded on three sides by water. As such, access is difficult and as the city grew, it could only spread in one direction without crossing water. ${ }^{8}$ Second, New York's primary industry, financial services, is both extremely information intensive and not a large consumer of land. The older New York industries (textiles, publishing) that had less need for up-to-the-minute knowledge and greater need for land have spread. Indeed, the difficult period in New York City from 1970 to 1990 reflected the disruptions caused by the exodus of those older industries. Third, New York is an older city and its infrastructure was built for higher density levels.

Los Angeles is often viewed as the paradigmatic sprawl city (Giuliano and Small 1991). It takes going out 11 miles from the central city of Los Angeles to find as large a share of employment as New York has within three miles. Los Angeles differs in industrial mix (it is one of the few large cities that have a larger share of employment in manufacturing

\footnotetext{
${ }^{7}$ As we do throughout the paper, we are here examining primary metropolitan statistical areas. We consider the consolidated metropolitan statistical area (CMSA) just too large to use meaningfully. However, there is no question that the measured centralization of New York City would decline if we looked at CMSAs.
} 
than does the U.S. as a whole). Los Angeles' port still has large, land-intensive employers. While Los Angeles does have knowledge-intensive employers, they are less in need of immediate information flows than finance. Los Angeles really came of age in the car era, so its infrastructure is aimed at lower density living. Finally, Los Angeles doesn't have the same natural barriers as New York City which would prevent the spread of population.

The surprise for us was Chicago, which is the third line on the graph. We had expected Chicago to resemble New York City or at least to lie half way between the Los Angeles and New York models. While there is slightly more employment centralization in Chicago than in Los Angeles, Chicago looks more like L.A. than it looks like New York City. When we plotted similar graphs for other cities, we were consistently amazed at the extent to which the employment patterns in other American metropolitan areas resembled those of Los Angeles far more than they resembled monocentric New York. This can be seen by comparing the L.A. and Chicago curves with those for the United States in Figure 1.

Our third figure shows the time series for centralization. As we do not have zip code data on employment for any time period prior to 1994, we are forced to use more standard county level measures to document the trends in centralization. The data source is the Department of Commerce Regional Economic Information System (REIS) CD-ROM. We use the share of employment and population working in the largest county of consolidated metropolitan areas from 1950 to 1990. This is a crude measure of centralization, but it still shows the basic pattern of declining centralization. In some sense, the surprise to us was not the amount of increasing decentralization. The fact that more than 50 percent of metropolitan area employment was outside of the largest county even in 1950 was startling. There are two possible interpretations of this fact. First, cities in 1950 may not have been monocentric even then. Second, Consolidated

\footnotetext{
${ }^{8}$ While we wish we could do more work on geography throughout this paper, data limitations restrict our ability to do much on this topic. We simply acknowledge that topography is clearly important and a pressing topic for future research.
} 
Metropolitan Statistical Areas may have contained several smaller monocentric cities in 1950.

\section{Our Regression Approach}

There are many summary measures that can capture the degree of employment centralization. For example, we have already discussed measures such as the share of employment with a three, or ten mile distance from the city center, and the distance between the median employee and the city center. However, for much of our work, we will use coefficients from the following zip code level regression:

$$
\log \left(\frac{\text { Employment }}{\text { Square Mile }}\right)=\alpha_{M S A}+\beta * \text { Distance from } \mathrm{CBD}+\varepsilon
$$

using our zip code data, where $\alpha_{M S A}$ is a MSA specific fixed effect. These density regressions are fairly standard in the literature (see DiPasquale and Wheaton, 1996) and is justified by an exponential density function (i.e., Density $=e^{-\beta^{*} d i s \tan c e}$ ). In some cases where there are zero values for many zip codes (i.e., the industry-city regressions), we work with one plus job density. The exponential density is justified in the population density literature by a power utility function. In the employment context, it can be justified by a Cobb-Douglas production function with land as an input. Generally, we run these regressions with metropolitan area fixed effects to account for higher employment densities in some metropolitan areas. If we run this employment regression for the entire United States (including the MSA fixed effects), we find an estimate of $\beta$ of -0.091 with a standard error of $0.001 .^{9}$ If we run the population gradient regression for the entire United States and include MSA fixed effects, we find an estimate of $\beta$ of -0.076 with a standard error of 0.001 .

\footnotetext{
${ }^{9}$ The MSA fixed effects allow some cities to have greater average density than others. If we did not include these fixed effects, the estimate of $\beta$ would be -0.058 . The lower coefficient results from the fact that cities which are lower density, on average, are also, on average, smaller geographically.
} 


\section{Decentralization across Metropolitan Areas and Regions}

We are not primarily interested in a single nationwide measure of employment decentralization. Our goal is to have measures that will enable us to compare across metropolitan areas and industries. ${ }^{10}$ To accomplish this aim, we estimate equation (1) separately for each MSA. Thus, each MSA has a separate intercept (which is close to the MSA fixed effect in the nationwide regression) and an MSA slope-which will be our measure of centralization. In general, there is a relationship between the MSA slope and the MSA intercept- the correlation is -0.67 . This means that in denser cities employment is more centralized.

Our regression-based measure is not the only possible measure of employment decentralization. For example, Chua (1999) uses the share of employment within a 3mile ring of the city center. Other possible measures include the share of employment within 10 miles of the city center, and the median distance between the city center and employees. While there are cases when one measure is theoretically preferable to another, generally there is not an overwhelming case for any particular measure. Ideally, the measures would all be highly correlated, but as Table 1a shows, correlations are far from perfect. As a result, we will generally show results both for the 3-mile ring employment share and for our basic elasticity measure.

Using either of these two measures, there is a striking degree of heterogeneity in the degree of centralization across metropolitan areas. Some cities have positive gradients, meaning that employment is generally larger away from the city center. Other MSAs are highly centralized. Figure 4 shows the histogram of our estimates. A typical standard error for one of these estimates is 0.03 - thus most of our estimates are significantly different from zero and many are significantly different from each other.

\footnotetext{
${ }^{10}$ A number of studies have measured employment decentralization in specific cities such as Houston (Mieszkowski and Smith 1991), Los Angeles (Giuliano and Small 1991), and Chicago (McMillen and McDonald 1998). Macauley (1985) reports evidence of the flattening of population, employment and manufacturing gradients for 18 cities between 1940 and 1980.
} 
Table 2 documents the heterogeneity of employment decentralization across regions. The first four columns show the mean value of four different measures of centralization by region. The rest of the table shows the five least and most centralized cities within each region. We show our basic regression measure of $\beta$ (see equation (1)), median distance to employee, and the share of employees within 3 mile and 10 mile distances. These measures have all been weighted by MSA population. It is very clear that the least centralized region is the Midwest. By every measure, it has the highest degree of employment sprawl. Its largest cities, such as Detroit and Chicago, are extremely decentralized. The South is clearly the second most decentralized region. This ranking holds up using all of our measures.

The most surprising element of the table is that by one of our measures, the West is the most centralized region, and by three of our measures it is second only to the East in centralization. Given the perception of some observers that the cities of the West are the most sprawled, it is surprising the West comes out as the most centralized region (at least by one of our measures). It is not surprising that the East is centralized. Of course, the East also has primary metropolitan statistical areas, such as Nassau, Long Island, which are decentralized. Naturally, if we used consolidated statistical metropolitan areas. some of these areas would be included in the more centralized, larger CMSAs.

\section{Decentralization across Industries}

There is also remarkable heterogeneity across industries. Substantial sprawl is ubiquitous, and there is a great deal of mass close to flat employment gradients, While some industries have remained quite concentrated. Figure 5 plots two industries that are at the extremes. Commercial banking is one of the most concentrated industries. About 50 percent of the employment in this industry lies within five miles of the city center. We suspect that this centralization may even have increased over time as deregulation of branch banking rules made it possible for large central city banks to expand elsewhere in the metropolitan area. Commercial banking uses little land and a great deal of information, so we are not surprised that it is one of the most centralized industries. 
"Carpets and rugs" is an industry at the other extreme. This is a low human capital industry that does involve physical infrastructure. It is among the least centralized of industries. Two-thirds of the industry works more than ten miles from the city center. Much of our empirical work in the rest of the paper will use cross-industry differences in centralization to understand what are the important forces that explain centralization

Our regression methodology can also be used to compare the levels of urban centralization across industries more rigorously. In this case, we estimate separate versions of equation (1) for each industry. Again, in each industry-specific regression we allow separate MSA fixed effects. In this case, the MSA fixed effect captures different employment densities in each industry in each MSA. One issue with this estimation is that in a large number of zip codes, there is zero industry employment. This censoring is clearly problematic and standard Tobit techniques will not handle it adequately (because they will still treat each zero observation identically, which will lead to estimating excessive flatness of employment densities). ${ }^{11}$

Figure 6 gives a histogram of estimated decentralization coefficients across 3-digit industries. A typical standard error for these regressions is 0.001 , so many of these coefficients are different statistically. The large number of basically zero coefficients is interesting, and appears to be robust to many alternative specifications of the equation.

In Table 1b, we show the correlation between 3-digit SIC specific estimates of equation (1) with the share of a 3-digit industry's total employment across all MSAs that is located in the inner three miles of the MSA and the share located in the inner ten miles of the MSA. These correlations are often low. Again, this low correlation supports our parallel

\footnotetext{
${ }^{11}$ To study the robustness of our SIC estimates of equation (1), we aggregated zip code employment by .5 mile rings. Thus, if the typical CBD's outer areas are 30 miles from the CBD then we construct 60 data points per industry. Estimating an employment gradient for this "aggregated data", we found the OLS gradient to be highly correlated with our estimates of equation (1). For a study that estimates separate equations for the probability that a geographical area contains employment and the level of employment conditional that employment is greater than zero see McMillen and McDonald (1998).
} 
use of both the regression-based measures and the share of employment within a three mile ring of the city center.

Table 3 shows the ten least and most centralized industries. Business and consumer services are highly represented among the most centralized industries. This connects with the work of Kolko (1998) who documented the extent to which high transport costs in services appears to keep them in the highest density areas. The least centralized industries tend to be connected with natural resources. Interestingly, there is no industry with a significant positive density gradient, while there are metropolitan areas with such positive gradients.

\section{Rethinking the Monocentric Model}

Among the most important consequences of the decentralization of employment is that the traditional monocentric model is becoming an increasing poor representation for the decentralized world (for a detailed discussion see Anas, Arnott and Small 1998). While there have been many critics of the monocentric models for decade, these criticisms have become more justified over time. We now look at three features of monocentric models and ask about the connection between these features and the decentralization of employment.

The first great triumph of the monocentric model is its ability to explain why housing prices decline with distance from the city center. Alonso's (1962) masterpiece illustrated how lower housing prices must compensate residents for the pains of commuting. But if jobs are decentralized, then commuting times may not decline with distance from the city center. As such, a second feature of the monocentric model is that commute times should rise with distance from the CBD. Again, we expect the distance-commute time relationship to disappear in decentralized metropolitan areas.

A final element of the monocentric model is that several versions of the model predict that the poor will live in the central city (Wheaton 1977). The classic version of the 
model argues that this comes about because of great demand for land among the rich. Other versions (see Gin and Sonstelie 1981, or Glaeser, Kahn and Rappaport, 2000) argue that this connection comes about because the poor use time-intensive public transportation. We examine whether the relationship between poverty and proximity to the $\mathrm{CBD}$ is weaker in decentralized cities.

To examine the first implication of the monocentric model-housing prices decline with distance from the city center-we begin by estimating a standard housing price gradient regression for each metropolitan area:

(2) $\log ($ Median Housing Price $)=\gamma_{M S A}+\chi_{M S A} *$ Distance from CBD

We are regressing the logarithm of home price at the zip code level on distance from the CBD and the coefficient $\chi_{M S A}$ is meant to capture the extent to which poverty falls with distance from the city center. We then plot this estimated $\chi_{M S A}$ coefficient against the MSA level employment density gradient (from estimating equation (1)) in Figure $7 .{ }^{12}$ Figure 7 shows the relationship between the slope of employment density on distance from $\mathrm{CBD}$ and the slope of housing price on distance from CBD. There is a strong and statistically significant positive connection between the two measures. In metropolitan areas where employment is centralized, housing prices decline with distance from the CBD. In decentralized metropolitan areas, this decline is much milder. Interestingly, even in cities where the employment gradient is flat, housing prices still decline with distance. Presumably this gradient reflects the consumer advantages of the city center (see Glaeser, Kolko and Saiz, 2001).

To test the second implication of the monocentric model- commute times rise with distance from the city center- we being by regressing median commute time (again, at the zip code level) on the distance from the city center for each metropolitan area:

\footnotetext{
12 The data source for all demographic data at the zip code level is the 1990 Census of Population and Housing.
} 
(3) $\log ($ Average Commute Time $)=\theta_{M S A}+\delta_{M S A} *$ Distance from CBD .

Average commute times come from the 1990 Census of Population and Housing's zip code residential file. For each zip code, the data set reports summary statistics for the residents who live there. The estimated coefficient $\delta_{M S A}$ reflects the extent to which commuting times rise with distance from the city center. ${ }^{13}$

In Figure 8, we look at the relationship between these estimated coefficients and our estimates of the employment density-distance from CBD. This figure shows the relationship between the slope of employment density on distance from CBD and the slope of commute times on distance from CBD. The graph indicates that in decentralized metropolitan areas, commute times barely rise with distance from the CBD (as in Gordon, Kumar and Richardson 1991). Naturally, when the jobs are in the suburbs, people in the suburbs have shorter commutes.

To separate whether sprawl has different effects on travel speed and distance, we use the 1995 National Personal Transportation Survey (NPTS). The 1995 NPTS is a nationally representative data set of over 20,000 households. It includes detailed information on worker commuting patterns. In Table 4, we present three OLS regressions. For each commuter who lives in a metropolitan area, we construct this commuter's miles per hour, one way travel time in minutes, and distance commuting. We regress the log of these three dependent variables on MSA fixed effects and the log of the population density at the census block where the respondent lives. Unfortunately, we do not know the distance to city center in this data set. However, we do know population density of the census block where the person lives, which serves as a rough proxy for degree of suburbanization. The three regressions in Table 4 show that across the U.S. as a whole, people in low density areas commute much longer distances but do so at much faster speeds. Kahn (2000) shows that vehicle mileage is much lower in denser metropolitan areas. The net effect is a mild negative connection between travel time and density. This suggests that in the previous graph, the low commute time-distance from CBD 
relationship in many cities combines the fact that in the suburbs, people are driving much further, much faster.

The final implication of the classic monocentric model is that income will be higher in the suburbs than in the city center. To see whether this fact is weaker in decentralized cities, we begin by estimating a regression (like equations (2) and (3)) where we regress median household income in each zip code on distance from the city center. Median household income by zip code is reported in the 1990 Census of Population and Housing zip code file. We compare across metropolitan areas and ask whether the connection between home prices and distance from CBD disappears in decentralized metropolitan areas. Figure 9 shows the relationship between this measure of the centralization of household income and our basic decentralization of employment measure. We find that in more decentralized cities, poverty is also more decentralized. This connection suggests that the poor may not be completely stuck in central cities and when the jobs are in the suburbs, they are also more likely to be in the suburbs.

A final question about the monocentric model is whether we should model edge cities as polycentric, or just diffuse. Several authors (Henderson and Mitra, 1994, Small and Song 1994) have put forth a polycentric view of edge cities. If these authors are right, we should appropriately model sprawled cities as just having multiple employment centers. We can then use the standard AMM model for thinking about patterns around these cities. An alternative view is that the patterns of employment in the suburbs bear no resemblance to patterns in the city center. According to this view, suburban employment is much more decentralized, and a better model posits that employment is spread evenly throughout the suburbs. Many policy analyses that hinge on the monocentric model (for example the location of the poor) need to be rethought if suburban employment is really not centered at all. ${ }^{14}$

\footnotetext{
${ }^{13}$ Our key results are unchanged if we weight the regressions by zip code population.

${ }^{14}$ For example, we might think that suburban employment may lead to pockets of poverty surrounding suburban employment centers if there are indeed such centers. However, if suburban employment is sufficiently decentralized this seems unlikely.
} 
To examine this question, we consider the amount of employment concentration in the most dense zip codes of the inner and outer areas of the city. To be precise, we first split each metropolitan area into an inner and an outer ring using the median distance from the CBD as the dividing line. We then sort zip codes by density and ask how much employment, in the inner and outer rings, was located in the most dense zip codes. Specifically, we summed up employment (going from densest to least dense zip codes) until we had included enough zip codes to account for five percent of the land area of the metropolitan area as a whole. Thus, we are considering the same land area in the inner and outer rings, and asking whether the densest zip codes in the outer ring are anywhere near as dense as the zip codes in the inner ring.

Table 5 shows the shares of population and jobs in these densest areas of the inner and outer rings of metropolitan areas. In 21 metropolitan areas, there are at least twice as many jobs in the central city centers than in the suburban centers. In many cities, the ratio of jobs in the central cities zip codes to jobs in the suburban zip codes is more than three. The ratios for population are generally smaller. This table clearly illustrates these two facts. First, there are some metropolitan areas (Detroit, Los Angeles, Tampa) where there are suburban centers which really do look like their central cities. On the other hand, in the vast majority of metropolitan areas, suburban employment is much more dispersed than central city employment. On the whole, we think that suburban employment is best thought of as being decentralized, not polycentered. This may help us to understand why suburban poverty is much less centralized (see footnote 12).

\section{The Basic Theory of Decentralized Employment}

We think of the decentralization of employment as the result of an economic equilibrium where firms and workers balance the benefits of density against density's costs. In this essay, we focus on the decisions of firms, but we think of workers as simultaneously making location choices. One pervasive question is whether the decentralization of firms is primarily a response to the demand of workers for suburban lifestyles or whether firms would have moved into suburbs on their own. This question is important because it helps 
us to understand whether cities should fight for employment by worrying about the productivity of employers or about the quality of life of employees. ${ }^{15}$

Arguably, the greatest theoretical achievement of urban economics is the Alonso-MuthMills framework for analyzing household location decisions within a metropolitan area (see Brueckner's 1987, particularly elegant synthesis). In this model, consumers choose their proximity to the city center trading high land prices against shorter commute times. In reality, at least two other sets of factors influence the location decision of consumers. Cities or suburbs may have amenities (attractive scenery, unsafe streets) which attract or repel consumers (see Brueckner, Thisse and Zenou, 1998). Political boundaries and public goods provision will also influence the locations of households. ${ }^{16}$ The location of households thus comes from the interplay of commuting times, home prices and the demand for land, non-government locational amenities and government. We believe that the dominant force explaining the rise in suburbanization since 1900 is the automobile, but other authors emphasize different factors. Margo (1992) attributes much importance to rising incomes that increase demand for low density dwellings. Gyourko and Voith (1999) point to government policies which favor suburban living. Mills (1992) argues that big city problems drive much of modern suburbanization.

While the location decisions of households have been studied extensively, the location decisions of firms have not. Several papers on decentralized employment looked at population patterns when firms were distributed in multiple locations within a city (e.g., White (1976, 1988), Ross and Yinger 1995). More recent work (e.g., Henderson and Mitra, 1996) has taken the location decision of firms more seriously and thought about the relative advantages of a central versus edge locale.

Decentralization of employment is the result of firms deciding that locating in the lower density urban fringe is more profitable than locating in the city center. Profits of firms can be written as:

\footnotetext{
${ }^{15}$ Elsewhere, one of us has argued that the future of cities lies in their ability to become attractive havens for consumers (Glaeser, Kolko and Saiz, 2001).
} 


$$
\mathrm{P}(\mathrm{i}) * \mathrm{~A}(\mathrm{i}) * \mathrm{f}(\mathrm{L}, \mathrm{X})-\mathrm{W}(\mathrm{i}) * \mathrm{~L}-\mathrm{C}(\mathrm{i}) * \mathrm{X}+\mathrm{e}(\mathrm{j}, \mathrm{i})
$$

where $\mathrm{P}(\mathrm{i})$ is a location-specific price net of transport costs, A(i) is location-specific productivity, $\mathrm{f}(\mathrm{L}, \mathrm{X})$ is a space indifferent production function in labor and a vector of other inputs $\mathrm{X}, \mathrm{W}(\mathrm{i})$ is a location specific wage, and C(i) is a vector of location-specific other inputs. The term $e(j, i)$ refers to a firm-location specific error term to capture heterogeneity across firm-location matches, with cumulative distribution function $F(e)$.

For simplicity, we just take the levels of $\mathrm{X}$ and $\mathrm{L}$ as fixed - this means that employment per firm is fixed and overall employment density moves only with the number of firms. Thus the overall level of employment in industry $\mathrm{j}$ in location $\mathrm{i}$ will be:

$$
\mathrm{L}^{*}(1-\mathrm{F}(\mathrm{P}(\mathrm{i}) * \mathrm{~A}(\mathrm{i}) * \mathrm{f}(\mathrm{L}, \mathrm{X})-\mathrm{W}(\mathrm{i}) * \mathrm{~L}-\mathrm{C}(\mathrm{i}) * \mathrm{X})
$$

Employment will be a function of 1) local prices of the final good and transport costs, 2) local productivity differences, 3) local labor supply, and 4) the cost of local inputs, especially land. If we believe that local productivity differences are tied primarily to local knowledge, then this grouping comes down to which locations have advantages in transport costs for goods, people, and ideas.

Which of these forces are likely to differ between cities and suburbs? Big cities may have some advantages in transport costs and prices of goods. They are large markets, and high density facilitates the access of customers (as in Krugman 1991). Also, many cities were built around ports or other transport hubs which also will attract high transport cost goods. However, the suburbs may have better access to highways and transportation infrastructure. Many of the most famous edge cities are strongly connected to these highways, for example the Rt. 128 corridor in Boston. As such, even if transport costs are an important determinant of location, we cannot say a priori whether cities or suburbs will particularly appeal to high transport cost industries.

\footnotetext{
${ }^{16}$ Glaeser, Kahn and Rappaport (2000) argue that the poor may disproportionately locate in central cities because suburban governments cater to the rich and big city governments cater to the poor.
} 
We will have four tests of the role of transport costs. First, we will look at whether industries that produce goods with a higher weight per dollar value are more likely to suburbanize. This just looks whether an increase in transport costs leads to suburbanization or centralization. Second, we will look at services versus manufacturing with the idea that services have higher transport costs. Even though services often have weightless products (e.g., haircuts), they require the provider and the consumer to be in the same physical place and this raises transport costs. Third, we will look at the extent to which across industries, goods are shipped abroad. Fourth, we will look at the extent to which industries whose customers are particularly centralized are themselves more centralized. The importance of this effect may differ across industries if some industries are likely to locate near customers and others are more likely to locate near suppliers.

A second possibility is that cities and suburbs differ in productivity, at least for some industries. One possible reason for greater urban productivity is that cities speed the flow of ideas. If firms in cities have access to more knowledge than firms in suburbs, then this will create an urban productivity advantage. Testing for the importance of intellectual spillovers is notoriously difficult. However, we expect that the demand for these spillovers will be higher in industries in which, 1) employees have higher levels of human capital, and 2) workers are more likely to use computers. We will therefore test whether high human capital and high computer use industries are more likely locate in the urban center.

The third factor that should influence the urban centralization of firms is the location of workers and the wages that they demand in the urban core relative to the fringe. This is a difficult phenomenon to test, because the location of workers is surely endogenous. Just as firms locate to be close to workers, workers locate to be close to firms. Indeed, one can imagine a situation with multiple equilibria. In one equilibrium, firms locate downtown and workers crowd near them. In another equilibrium, firms decentralize and workers locate in suburbs. One interpretation of the urban transformation is that firms and workers are just moving from one equilibrium to another. Of course, it is foolish to 
believe that the edge city equilibrium could have existed in a world without automobiles, but once automobiles are widespread then both equilibria may exist simultaneously.

The mutual causality between firm and worker location makes its particularly hard to try to isolate causal factors in employment decentralization. Despite a heroic effort by Thurston and Yezer (1994), who rely on the timing of decentralization to identify causality, it is still quite difficult to estimate whether jobs are following people or vice versa. ${ }^{17}$ We have three approaches to this issue. First, will look at whether there is more suburbanization in industries where workers are predicted to suburbanize based on their demographics. Then we examine the decentralization of industries in cities where suburban location is particularly common among the types of workers that these industries generally hire nationwide. Finally, we will look at whether employment growth has followed population suburbanization in the time series across metropolitan areas.

\section{Explaining Decentralization across MSAs}

Now we return to our empirical work and test the hypotheses about employment sprawl discussed in the previous section. First, we examine the correlates of sprawl at the MSA level. Second, we consider the correlates of decentralized employment across three-digit industries.

\section{Population and Employment}

One question that will recur throughout this paper is the extent to which the suburbanization of employment is driven primarily by the suburbanization of jobs. Figure 10 graphs employment-distance density gradients on population-distance density gradients across metropolitan areas. There is a strikingly positive relationship. Cities that have decentralized populations have decentralized employment. The correlation between these two measures is .79. Of course, this connection does not suggest any

\footnotetext{
${ }^{17}$ For another example of time series identification methods see Greenwood and Stock (1990).
} 
causality, but the closeness of the two measures does suggest that it is difficult to think of the decentralization of employment without considering the decentralization of population.

Table 6 asks whether there are any cities with decentralized employment which do not have decentralized population. To answer this question, we regress the employment density-distance gradient on the population density-distance gradient (as in Figure 10) and then examine the residuals. Our goal is to show cities that appear to be particularly centralized or decentralized in their employment over and above the extent predicted by the suburbanization of population in the city.

The table shows an interesting set of outliers. Las Vegas, which is fairly centralized along both dimensions, has a surprisingly high level of population centralization. The regression predicts that employment will generally be more centralized than population, but for Las Vegas, that is not the case. The other extreme is Chattanooga, Tennessee, where employment is much more centralized than population. In most cases employment and population go together, and we are driven to believe that the connection between the two types of decentralization is extremely strong.

\section{City Age and Decentralization}

A second preliminary hypothesis is that heterogeneity across metropolitan areas occurs only because some cities were built earlier than others. This theory argues that decentralization of employment is inevitable and that the only reason centralized cities exist is that they were built in an era before automobiles. Figure 11 shows the connection between the age of the city (measured as years since incorporation of the largest city) and our measure of decentralization. There is a connection-older cities are more centralized-but the connection is surprisingly weak. This is also true when we use alternative measures of city age (e.g., the first year it hit some population mark). The pattern shown by Figure 11 is that all of our oldest cities (over 200 years) are reasonably centralized, and all of our newest cities (under 60 years) are reasonably decentralized. 
However, in the range between 60 and 200 years old (which includes most cities) there is considerable heterogeneity. There is clearly a connection between age and decentralization, but it does not suggest a deterministic relationship where age determines centralization.

While overall city age is not correlated with city decentralization, cities with newer suburbs are more decentralized. This is not surprising. After all, one hundred years ago, centralization was ubiquitous. The cities that have decentralized have almost by definition grown along their edges. Figure 12 shows this fact. We first regress the age of the housing stock on the distance from the city center for each metropolitan area. Cities with a high value for this parameter have large gaps between the age of their central cities and the age of the suburbs. We find that cities where this gap is largest are those which have had the most decentralization of employment. There is no question that decentralized employment required recent construction and urban change, but much of this urban change occurred in metropolitan areas with relatively old central cities. Thus, there is no guarantee that the older cities will not decentralize.

\section{Table 7-Cross MSA Regressions}

In Table 7, we look at the determinants of MSA concentration. We use two measures. First, we use our employment density-distance gradient in regressions (1)-(3). In these regressions, the dependent variable is itself the estimated slope from a first stage regression where employment density is regressed on distance from CBD. Our second dependent variable (used in regressions (4)-(6)) is the share of employment more than three miles from the CBD. Most of our results are consistent across the two measures of decentralization.

Regressions (1) and (4) show our basic control variables. The first three variables are region dummies; the omitted region is the Northeast. The Midwest is generally the most decentralized region when there are few other controls. We interpret the coefficient of .043 in regression (1) as meaning that, on average, employment density falls 4.3 percent 
more with each mile from the CBD in the Northeast than it does in the Midwest. The coefficient of .035 in regression (4) can be interpreted as meaning that 3.5 percentage points of the metropolitan area's employment lies within a 3-mile radius of the city center in the Northeast than in the Midwest. The West and the Northeast are the most centralized regions.

In all of our regressions, we also control for city age, metropolitan area population and the land area of the metropolitan area. Older cities are weakly more centralized. As discussed above, we are surprised by the weakness of the age effect. MSA population is positively correlated with centralization, and metropolitan land area is negatively correlated with centralization in regression (1) and positively correlated with centralization in regression (4). The land area variables are generally insignificant. The MSA population coefficient means that as metropolitan area doubles 2.5 percent more of the metropolitan area's population lives outside of the three mile inner ring. More populous metropolitan areas appear to be more decentralized.

Regressions (2) and (5) show our demographic and industry controls. The demographics have weak effects that occasionally flip between our two specifications. The industry controls are extremely powerful. The share of the labor force in manufacturing strongly predicts decentralization and the share of the labor force in services strongly predicts centralization. As discussed above, we interpret these results as suggesting that manufacturing is a land intensive good with low transport costs, which is sensibly located in low density areas. Services have higher transport costs and therefore, locate in high density areas that are close to consumers.

Our final regressions, (3) and (6), control for the number of political jurisdictions in each metropolitan area. We hypothesize that places with more fragmentation would see more decentralization for Tiebout-like reasons. Some firms might decentralize to be in a different political jurisdiction (and presumably receive a different bundle of public goods) in cities that are politically fragmented. In single government cities, there would be little gains from decentralization. Indeed, this seems to be the case. As the number of 
jurisdictions in a metropolitan area doubles, the share of people working outside of the three mile ring rises by 6.3 percentage points. There seems to be some evidence for some political roots of decentralization and we will return to evidence on politics and decentralization later on.

\section{Explaining Employment Decentralization across Industries}

We now switch to explaining the level of decentralization across industries. Our key dependent variable will be the employment density - distance elasticity estimated above using equation (1). In this case, first stage regressions were run at the industry level where employment density (across all urban zip codes) was regressed on distance from $\mathrm{CBD}$ and metropolitan area (industry specific) fixed effects. In Tables $8 \mathrm{a}$ and $8 \mathrm{~b}$, we look across industries at the determinants of industry level employment decentralization. In Table 8a, the dependent variable is an estimate of equation (1) for a specific three digit SIC industry. There are 439 observations, one for each 3 digit industry in our database. Table $8 \mathrm{a}$ shows results using our density-distance gradient and table $8 \mathrm{~b}$ gives results using the share of workers outside of the 3-mile ring surrounding the metropolitan area. ${ }^{18}$

Regression (1) in each table shows our three basic variables. The first variable is a worker national suburbanization index. This index is created by first estimating a linear probability model using the 1990 Census of Population and Housing micro data where we predict the probability that a household head with given demographics lives in the suburbs:

$$
I_{\text {Suburbs }, i}=\sum_{j} \beta_{j} X_{j, i}+\varepsilon_{i}
$$

where $I_{\text {Suburbs,i }}$ is an indicator variable that takes on a value of one if person "i" lives in a suburb, and $X_{j, i}$ reflects characteristic $\mathrm{j}$ of worker i. Then we use the values of $\beta_{j}$ 
estimated from this micro-regression in combination with the average values of each characteristic for each industry, $\mathrm{k}$, denoted $\hat{X}_{j, k}$. These industry averages come from the 1990 Census as well. We then form $\sum_{j} \beta_{j} \hat{X}_{j, k}$ as the predicted suburbanization index for each industry.

A second variable is meant to capture the degree to which an industry's suppliers are located in the suburbs. We use the Bureau of Economic Analysis's Commodity by Industry Direct Requirements, 1992 Benchmark matrix for 97 two digit SIC industries. For each industry, we calculate the share of total inputs it purchases from every other industry. Then we use the 1996 Zip Code Employment File to calculate its "national suburbanization rate". This is defined as the share of national jobs located more than ten miles from a metropolitan area's CBD. We calculate the average national suburbanization of its input suppliers for each industry. As we discuss below, we also calculate the input supplier suburbanization index by MSA/SIC. Intuitively, the input supplier index is high if an industry purchases most of its inputs in production from industries that are concentrated in the suburbs. More formally we compute:

(7) Input Suburbanization $=\sum_{j} \varpi_{k}^{i} s_{k}$,

where $\varpi_{k}^{i}$ is the share of industry i's inputs which are bought from industry $\mathrm{k}$ and $s_{k}$ is the share of industry k's workers that are themselves suburbanized. In practice, we are missing data on this variable for many industries. We have dealt with this by setting this value to the mean level of the index for the missing data points and including a dummy variable to indicate when their data was missing.

A third basic variable is a dummy variable that equals one if the industry is in manufacturing and zero otherwise. As we saw in the previous table, there appears to be a

\footnotetext{
${ }^{18}$ To test for robustness, we have estimated this regressions by combining employment across metropolitan areas within .5 mile rings and then estimating density-distance gradients with this aggregate. These results are quite similar to estimates found using the unadjusted zip code data.
} 
strong connection between manufacturing and decentralization. Our fourth basic control is average firm size. This variable comes from the 1996 Zip Code Employment file. As discussed by Chinitz (1961), dense cities may have a comparative advantage in providing inputs for non-vertically integrated firms. Alternatively, firm size may be capturing something about the degree of entrepreneurship and it may be that dense urban areas both help in the creation of new ideas (which would create a connection between smaller, newer firms and dense urban centers).

In Tables $8 \mathrm{a}$ and $8 \mathrm{~b}$, the variables generally have the expected signs. Manufacturing industries are much more likely to locate outside of the three mile ring and they have much flatter employment density-distance gradients. The magnitude of the manufacturing dummy is noticeably smaller here than in Table 7. One possible reason for this discrepancy is that the impact of manufacturing on urban form is not just limited to the suburbanization of those firms in manufacturing. Other related industries that share inputs (including labor) or that buy or sell to manufacturers may also suburbanize in high manufacturing cities. This cross-industry effect might explain why the MSA level coefficients on manufacturing are higher than the industry level coefficients on manufacturing.

The worker suburbanization index has a large effect on decentralization employment. Predicted worker suburbanization is the best predictor of industry suburbanization across all the regressions-- this is the first important fact in the table. The magnitude in Table $8 \mathrm{~b}$ suggests that for each worker who is predicted to suburbanize in residence, .86 workers are predicted to work outside of the three mile inner ring. Of course, the causality of this relationship is not obvious. Firms that have a comparative advantage in suburbanizing would be likely to hire workers who are also likely to suburbanize.

The effects on suburbanization of inputs are less robust. In the first regressions of Table $8 \mathrm{a}$, it appears that the input suburbanization measure is as important as the worker suburbanization measure. However, in the latter regressions of that table and in Table 8b, the effects of input suburbanization disappear. We are left believing that there remains 
considerable uncertainly about the importance of input location in driving the suburbanization of industry.

Finally, we do not see the expected firm size effect. There is no significant relationship across our entire sample between firm size and central urban location. Furthermore, it appears (weakly) that bigger firms are slightly more likely to locate within the central city.

In regressions (2) of both tables, we examine the impact of human capital variables that are meant to get at the intellectual intensity of each industry. This addresses the possibility that firms are staying in central cities to exploit the comparative advantage that dense areas have in the transfer of ideas. Regression (2) of Table 8a shows that increases in both high school and college education strongly increases the degree to which firms are centralized. In Table $8 \mathrm{~b}$, we find that there is a strong, positive effect of college education on locating inside the inner ring, but industries with more high school graduates (who do not finish college) are less likely to urbanize. This suggests a nonmonotonic relationship where the central industries have both the most skilled and the least skilled workers.

Figure 13 shows this relationship graphically by illustrating how centralization of employment rises with the education level of the industry. In this figure, the only exception is that the industries who use many high school dropouts are particularly likely to centralize. This may be because those workers are more likely to live in urban centers (as in Glaeser, Kahn and Rappaport, 2000).

In regression (3) we look at the share of industry employees using computers. ${ }^{19}$ In this case, there is a weak effect that is statistically insignificant in 8a and statistically significant in $8 \mathrm{~b}$. It again seems that the more intellectually intensive industries are more likely to centralize. This is the second important fact from these tables: variables that relate to human capital or intellectual content predict centralization. We see this and the

\footnotetext{
${ }^{19}$ The data source is the U.S Census web page.
} 
human capital results as evidence for the view that central cities do specialize in ideaintensive industries.

Regressions (4)-(7) use data that is only available for manufacturing industries. As such, we are forced to use a smaller sample of three-digit manufacturing industries and to drop the manufacturing dummy from our regressions. There are three major changes in our control variables. First, the importance of worker location becomes even stronger. It seems that manufacturing firms, more than other firms, may be strongly driven by worker location (see also Dumais, Ellison and Glaeser, 1997, for evidence on this). Second, as mentioned earlier, the effect of input suburbanization changes signs. Third, the firm size coefficient switches and becomes significant in both tables. Now we see the expected Chinitz effect where larger firms have less to gain from dense cities. Further work will be needed to understand why this effect appears only to work in manufacturing.

Regression (4) in each table examine our foremost measure of transport costs: dollar value per pound of output. ${ }^{20}$ If goods weigh little (per dollar value of output), then they are easy to transport. If they weight more, then they are harder to transport. As these goods are rarely sold directly to consumers (and particularly rare to consumers in the production locale), we expect the heavy products to locate away from the city center where they have better access to transportation hubs. This is what we find. Industries with higher transport costs are more likely to suburbanize their employment. This supports the view that urban advantage in reducing transport costs has become reasonably weak.

In regression (5), we look at whether or not the good is exported. ${ }^{21}$ Goods that are exported presumably have little value in being close to the urban market and much value in getting easy access to the highway network. As such, they were predicted to be

\footnotetext{
${ }^{20}$ The 1972 Census of Transportation provides information on the median value of output per pound of output by industry.

${ }^{21}$ Export is constructed using data from the NBER web page. Feenstra (1997) has posted data on U.S imports and exports in 1992. Bartelesman and Gray (1996) have produced the NBER productivity data base. We use their information on industry value added. Combining the two data sets allows us to construct
} 
suburbanized and that seems to be the case in Table $8 \mathrm{a}$. In Table $8 \mathrm{~b}$, the coefficient goes in the same direction, but it is not significant. The third interesting fact from this table is that there is some evidence that exporting and having high transport cost products leads to decentralized employment, yet this evidence is not all that compelling.

We do not have land use at the industry level. It is possible to get expenditures on real estate. Unfortunately these are often highest in industries that locate in central cities and use little actual space. Instead, we will use energy expenditure as a proxy for physical space. Table 8a shows that those industries with more energy per dollar of output are more likely to suburbanize. Table $8 \mathrm{~b}$ shows an insignificant result in the opposite direction. Regression (7) puts all three variables in together. In Table 8a, the only significant variable remaining is exported production. In Table $8 \mathrm{~b}$, none of the last three variables are significant.

In Table 9, we pursue two of these facts a little further. Here we examine densitydistance gradients that are industry-MSA specific. A unit of observation is the gradient of a particular industry in a particular metropolitan area, e.g., steel in Pittsburgh. In other words, we estimate:

(8) $\beta_{M S A, I N D}=\alpha_{M S A}^{1}+\alpha_{I N D}^{2}+\sum_{z} \phi_{z} X_{M S A, I N D}^{z}+\varepsilon_{M S A, I N D}$,

where $\beta_{M S A, I N D}$ is the slope of employment density on distance from CBD first estimated in an MSA-specific, industry-specific version of equation (1). In all of our second stage regressions, we include both MSA-fixed effects and industry-fixed effects $\left(\alpha_{M S A}^{1}\right.$ and $\alpha_{I N D}^{1}$ respectively), so that all results need to be considered relative to industry-MSA average. Our goal is to estimate the impact of MSA/industry specific explanatory variables (denoted $X_{M S A, I N D}^{z}$ ). We have omitted MSA-industry pairs where more than 90 percent of all zip codes have zero employment.

the share of industry output that is exported. This variable can only be constructed for manufacturing 
We include MSA fixed effects, and some form of industry fixed effects. Thus, we will no longer be interested in general industry or general MSA characteristics. Rather, we focus on the interaction between particular industry and MSA features.

In our first two regressions of Table 9, we examine the suburban population index and the suburban input supplier index in more detail. To generate this suburban index, we first estimate separate versions of the household suburbanization probability model for each MSA. For each MSA we have separate OLS coefficients which predict suburbanization. For example, in some MSAs, older workers may all suburbanize. In others, there will be more older workers still living in the central city. We then, as before, interact the coefficients from this regression with the average characteristics for the industry as a whole in the United States. Thus, for each metropolitan area-industry pair we can estimate a separate probability of suburbanization based on the suburbanization proclivity of the MSA as a whole and the industrial characteristics of the industry outside of the MSA. $^{22}$

In principle, this will address some of the endogeneity discussed above. Recall that the primary endogeneity issue is that firms that decentralize for exogenous reasons will be more likely employ workers from the suburbs. In this case, we use industries that are more likely to hire certain types of workers at the national level and are particularly likely to suburbanize in cities where those workers are suburbanized. Since we are controlling for industry and city fixed effects, we are only looking at the extent to unusual suburbanization of particular types of workers in a given city raises the suburbanization of industries that are likely to hire those sort of workers. Our basic assumption is that each city is small relative to total industry employment (so that the particular

industries. Energy is the expenditure on energy inputs per dollar of value added.

${ }^{22}$ To construct the worker suburbanization index, we use the 1990 Census of Population and Housing to calculate who is the "average" worker for each 3 digit industry using the national sample. In particular, we calculate the share of each industry's workers who are black, high school graduates, college graduates, and their average age. Define industry j's worker demographic vector as X(j). We use the Census data to estimate a linear probability model by MSA of household suburbanization. Define MSA m's estimated coefficients as $B(m)$ The suburbanization index for demographic group $j$ living in MSA $m$ is then $B(m) * X(j)$. 
suburbanization patters of that city will not drive the suburbanization of nationwide industry) and that each industry is small relative to total city employment (so that the industries suburbanization within that city will not drive the suburbanization of city-wide population).

We also estimate separate input supplier suburbanization measures for each metropolitan area as well. In this case, we take the nationwide input-output matrices and interact them with the extent to which other industries in that metropolitan area suburbanize. Thus, we use the extent to industry a's input suppliers (based on nationwide measures) are disproportionately suburbanized in msa $b$.

We show the results using employment-density regressions in regressions (1)-(2) in Table 9. As usual, the dependent variable comes from a first stage regression where employment density is regressed on distance from CBD for each MSA - industry pair. The regressions include different levels of SIC fixed effects. These SIC fixed effects serve to eliminate a relationship that might exist because the employment in the nation as a whole might respond to the degree to which the industry is suburbanized. We show results for two digit and three digit SIC codes. Both variables are significant in both specifications with plausible magnitudes. On the whole, we see this as further evidence for the importance of employee residential demand in driving the decentralization of industry.

In regressions (3) and (4), we rerun the regressions using share of employment outside of three miles of the city center. Again, the results are significant and the magnitudes are plausible. This supports the importance of workers suburbanization in driving the suburbanization of firms. This also suggests that input linkages may be important as well.

Table 10 presents one final piece of evidence on the relationship between job and worker location. This table attempts to exploit the timing of suburbanization to understand the nature of the jobs-workers relationship. Here we ask whether the suburbanization of 
employment has been faster in those areas with more initial suburbanization of population. Has the suburbanization of employment been following the suburbanization of population? Our basic approach is to estimate the following regression:

(9) $\frac{\text { Suburban } E p_{97}}{\text { MSA Emp }_{97}}-\frac{\text { Suburban Emp }_{69}}{\text { MSA Emp }_{69}}=\mathrm{B} \frac{\text { Suburban Pop }_{69}}{\text { MSA Pop }_{69}}+\varepsilon$,

where Emp represents employment in the suburbs and Pop represents residential population in the suburbs. We also include an intercept, region fixed effects, and unreported demographic controls. We are particularly interested in the coefficient on the initial suburban population share. Suburbs and central city are defined just at the county level. We define the central county as the county with the largest population in 1969, and the suburbs as the residual.

In the first regression, we find that as the initial suburban population share rises by 10 percent, the growth in suburban employment is .5 percent higher. Regressions (2)-(5) repeat this regression for different subsectors of the economy. It appears that manufacturing, and finance, insurance, and real estate are particularly likely to respond to the initial population share. Services are somewhat less mobile and more likely to stay in the city. While one might think that services are particularly likely to move close to people, services also have the highest transport costs and therefore might stick in the high density area where transport costs are minimized (Kolko, 1999). ${ }^{23}$ Finally, the government sector is by far the least mobile. This final result is not surprising and suggests that government jobs have often made up for the exodus of private sector manufacturing jobs. This table provides more evidence suggesting that increasing mobile firms are moving to where people want to live.

\section{Politics and Decentralization}

\footnotetext{
${ }^{23}$ Services include both business and consumer services.
} 
Our last and most preliminary work examines political borders. One serious issue in the decentralization of jobs is whether this decentralization has occurred because of "natural" economic forces or whether or not it is the result of various forms of government interference. Certainly, as Gyourko and Voith (1998) and Voith (2000) have argued many national policies may have influenced the suburbanization of population, and through that the suburbanization of industry. We are not going to address this possibility. Instead, we will look at whether the decentralization of industry is influenced by local governments.

There are two clear hypotheses about local governments and the suburbanization of industry. One hypothesis is that industry has suburbanized because of local governments that are bent on redistributing income using the tax base of local industry. As governments raise taxes, firms flee and industry decentralizes. It is easy to believe that the policies of mayors like John Lindsay or James M. Curley encouraged firms to flee the borders of New York City and Boston respectively. On the other hand, many suburban communities specifically oppose negative externality-creating firms, and as a result, these firms may cluster in the more friendly central cities

To test between these hypotheses, we use the following regression:

$$
\log \left(\frac{\text { Employment }}{\text { Population }}\right)=f(\text { Dis } \tan c e)+I_{\text {Central City }}+\varepsilon
$$

where $\mathrm{f}($ Distance $)$ represents a fairly flexible polynomial (including logarithms, quadratic and third order terms) and $I_{\text {Central City }}$ is a dummy variable that takes on a value of one if the zip code is within the central city's political boundaries. ${ }^{24}$ The interpretation of $I_{\text {Central City }}$ is that this variable captures the extent to which employment lies disproportionately within the central city boundary, holding constant the distance from the city center. We are looking for boundary effects. In a sense, the point is to see

\footnotetext{
${ }^{24}$ The MSA's center city is defined to be the city within the MSA that has the largest population.
} 
whether there are border effects holding distance constant. We are following the methodology of Holmes (1998) and others in this procedure. In our own previous work (Glaeser, Kahn and Rappaport, 2000), we have done this for poverty rates and central city boundaries and found quite significant border effects which we interpret as meaning that central cities disproportionately attract the poor.

However, in this case, there is no uniform central city effect. For some metropolitan areas, the central city is profoundly negatively associated with employment density. For others, employment shoots down when you cross the border into the suburbs. We interpret this heterogeneity as suggesting that some center cities are relatively business friendly (relative to the suburbs) and that in some metropolitan areas, the suburbs are quite friendly relative to business. Table 11 shows the list of the 10 largest and 10 smallest border effects by center city.

We looked for patterns in these border effects and found three basic facts. First, there are very clear regional effects. In the South and the Midwest, employment seems to be particularly high in the central cities. In the West, central city employment is particularly low. In the Northeast, border effects just appear to be small. Figure 16 shows these patterns.

In Figure 14, we document that in larger MSAs, border effects are more likely to be negative. It appears that in these bigger MSAs, the central cities are more likely to be anti-business than pro-business. It is in the smaller MSAs where center cities are really magnets for employment density. Perhaps this occurs because the central cities in the largest MSAs are bigger and try to exploit firms more fully because of their greater market power.

Third, in Figure 15, we show a strong connection between these center cities effects and the urbanization of poverty. The more that poverty was centralized in the main city, the more that these border effects occur. In principle, this might reflect reverse causality where poverty is higher in the centers in these cities because the firms have left (Kain 
1968). Alternatively, this might reflect the possibility that the poorest cities engage in the most redistribution and this scares firms away.

\section{Conclusion}

This paper has tried to establish a set of core facts about the decentralization of employment. First, while there is considerable heterogeneity across cities and industries, it is very clear that most of America is fairly decentralized. Across regions, the share of employment within 3 miles of the city center is never more than 19 percent. The typical American city looks much more like Los Angeles than like New York City.

Second, in these decentralized cities the basic Alonso-Muth-Mills framework no longer describes reality. In decentralized cities, commute times barely rise with distance. We believe that this occurs because increases in commuting distances are offset by increases in commuting speed. In decentralized cities, housing prices do not fall with distance from the city. Finally, as cities become more decentralized the central city-suburb poverty gap also falls. The basic theoretical framework of urban economics really doesn't operate well in America's sprawling metropolises.

Third, across metropolitan areas the best predictors of decentralization appear to be the industrial mix. Cities that specialize in services are relatively centralized. Cities that specialize in manufacturing tend to sprawl. This connection between manufacturing and decentralization is also seen in the cross-industry data. Manufacturing is more land intensive and cheaper to transport than services, which naturally gravitate to high density areas.

Fourth, across industries, high human capital measures and, to a lesser extent, the use of computers positively predict the degree of centralization. Industries which appear to be idea-intensive are more likely to locate in the central city. This may come about because dense urban areas facilitate the speedy flow of ideas and industries which are more ideaintensive want to locate in denser areas. 
Fifth, the strongest determinant of whether an industry locates in the center city or the suburbs is its labor force. Using both cross industry and industry-MSA combined variation, we find that in cases where the workforce is predicted to live in suburban areas, the firms will also locate in suburban areas. This suggests to us that the primary determinant of the degree of suburbanization is the demand of workers for suburban lifestyles.

Finally, there is evidence that political borders matter. In many cities, there are significant effects of political boundaries on the employment to population ratio. However, these effects differ across metropolitan areas and it is not on yet obvious if central cities are particularly friendly or hostile to firms. However, it does appear to be true that the central cities of the East and the West are least friendly to business and the central cities of the South and the Midwest are the most friendly to employment. These issues clearly need future research. 


\section{References}

Anas, Alex and Richard Arnott and Kenneth Small. (1998). Urban Spatial Structure. Journal of Economic Literature. Vol. 36(3), 1426-1465.

Alonso, William. Location and Land Use. Cambridge: Harvard University Press, 1964.

Bartelsman, Eric and Wayne Gray. The NBER Manufacturing Productivity Database. NBER Working Paper, \# T0205, October 1996.

Brueckner, Jan K (1987). "The Structure of Urban Equilibria: a Unified Treatment of the Muth-Mills Model," in ed. E. S. Mills Handbook of Regional and Urban Economics (Vol. 2). 821-845.

Brueckner, Jan, J-F, Thisse and Y. Zenou (1999) "Why is Downtown Paris So Rich and Detroit So Poor? An Amenity Based Explanation," European Economic Review. 43(1) 91-107.

Carlino, Gerald. (1985) "Declining City Productivity and the Growth of Rural Regions: A Test of Alternative Explanations". Journal of Urban Economics 18(1) 11-27.

Chua, H. (1999) "Employment Decentralization," Harvard University, Undergraduate Thesis.

Cooke, Timothy. (1983) "Testing a Model of Intraurban Firm Location". Journal of Urban Economics. 13 257-282.

DiPasquale, Denise and William C. Wheaton. Urban Economics and Real Estate Markets. Englewood Cliffs, New Jersey: Prentice Hall, 1996.

Dumais, Guy, Glenn Ellison and Ed Glaeser (1997) Geographic Concentration as a Dynamic Process, NBER Working Paper \#6270.

Feenstra, Robert C. "NBER Trade Database, Disk 3: U.S. Exports, 1972-1994, with State Exports and Other U.S. Data" NBER Working Paper no. 5990, April 1997.

Garreau, Joel. Edge City: Life on the New Frontier. New York: Anchor Books, 1992.

Gin, Alan and Jon Sonstelie. (1992) "The Streetcar and Residential Location in Nineteenth Century Philadelphia" Journal of Urban Economics, 32 92-107.

Giuliano, Genevieve. and Kenneth Small. (1991) "Subcenters in the Los Angeles Region”. Regional Science and Urban Economics. 21(2) 163-182. . 
Glaeser, Edward. (1998) “Are Cities Dying?” Journal of Economic Perspectives Spring Vol. 12 Number 2, 139-160.

Glaeser, Edward, Matthew E. Kahn and Jordan Rappaport (2000). "Why do the Poor Live in Cities?” NBER Working Paper \#7636.

Glaeser, Edward, Jed Kolko and Albert Saiz (2001) "Consumer City," Journal of Economic Geography, forthcoming.

Gordon, Peter, Ajay Kumar and Harry Richardson. (1991) "The Influence of Metropolitan Spatial Structure on Commuting Time" Journal of Urban Economics. 26(2) 138-151.

Greenwood, Michael and Richard Stock (1990). "Patterns of Change in the Intrametropolitan Location of Population, Jobs and Housing." Journal of Urban Economics 28: 243-276.

Gyourko, Joe and Richard Voith. "The Tax Treatment of Housing: Its Effects on Bounded and Unbounded Communities," Federal Reserve Bank of Philadelphia Working Paper 98-23, December 1998.

Henderson, Vernon; Mitra, Arindam. (1996) The New Urban Landscape: Developers and Edge Cities. Regional Science and Urban Economics;26(6) pages 613-43..

Holmes, Thomas. (1998) The Effect of State Policies on the Location of Manufacturing: Evidence from State Borders. Journal of Political Economy ;106(4), pages 667-705.

Kahn, Matthew (2000) "The Environmental Impact of Suburbanization," Journal of Policy Analysis and Management 18(4): 569-586.

Kain, John. (1968) Housing Segregation, Negro Employment and Metropolitan Decentralization, Quarterly Journal of Economics 82(2) 1968 175-197

Kolko, Jed. (1999) "Can I Get Some Service Here? Service Industries and Urban Density" Harvard University Mimeography.

Krugman, Paul (1991) Geography and Trade. Cambridge: MIT Press.

Macauley, Molly (1985). Estimation and recent behavior of urban population and employment density gradients. Journal of Urban Economics 18: 251-260.

Margo, Robert. (1992) Explaining the Postwar Suburbanization of the Population in the United States; the Role of Income, Journal of Urban Economics 31, 301-310.

McMillen, Daniel P. and John F. McDonald (1998). "Suburban Subcenters and Employment Density in Metropolitan Chicago." Journal of Urban Economics 43: 157180. 
Mieszkowski, Peter and Barton Smith. (1991) "Analyzing Urban Decentralization: The Case of Houston” Regional Science and Urban Economics. 21(2). 183-199.

Mieszkowski, Peter and Edwin Mills. (1993) The Causes of Metropolitan Suburbanization. Journal of Economc Perspectives V7; n 3 135-147.

Mills, Edwin. (1992) The Measurement and Determinants of Suburbanization. Journal of Urban Economics; 32(3), 377-87.

Muth, Richard. Cities and Housing. Chicago: University of Chicago Press, 1969.

Ross,Stephen and John Yinger. (1995) :Comparative Static Analysis of Open Urban Models with a Full Labor Market and Suburban Employment. Regional Science and Urban Economics;25(5) 575-605.

Small, Kenneth and Shunfeng Song. (1994). Population and Employment Densities: Structure and Change. Journal of Urban Economics. 36(3) 292-313.

Thurston, Lawrence and Anthony Yezer. (1994) Causality in the Suburbanization of Population and Employment. Journal of Urban Economics; 35(1), 105-18.

Voith, R. (2000) Brookings-Wharton Papers on Economic Activity 1:

Warner, 1975

Wheaton, William. (1977) Income and Urban Residence: An Analysis of Consumer Demand for Location. American Economic Review, 1977 620-634.

White, Michelle. (1976) "Firm Suburbanization and Urban Subcenters." Journal of Urban Economics 3: 323-343.

White, Michelle. (1998) "Location Choice and Commuting Behavior in Cities with Decentralized Employment," Journal of Urban Economics 24(2): 129-52. 
Figure 1

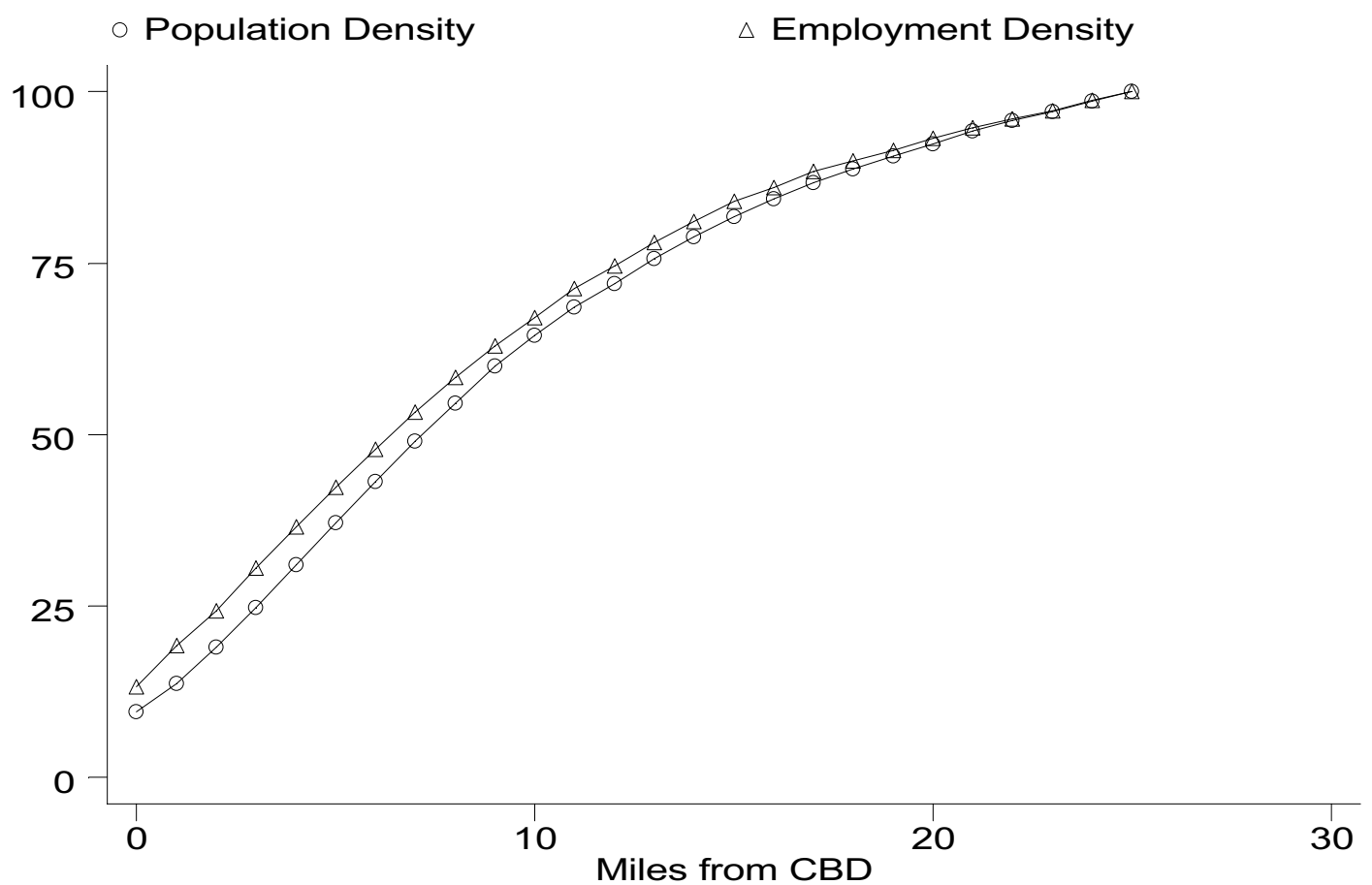

The Distribution of People and Jobs in Metro Areas 
Figure 2

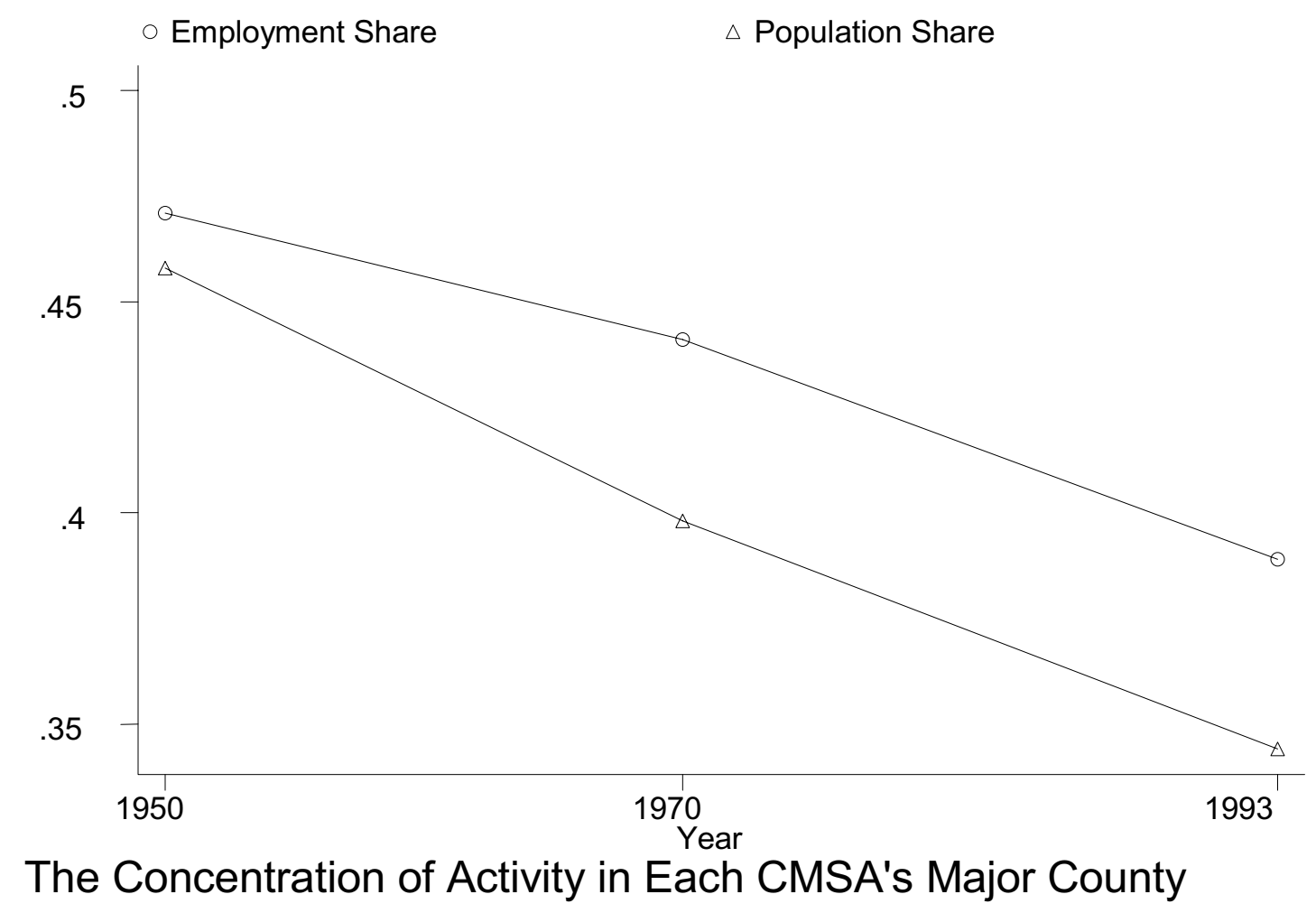


Figure 3

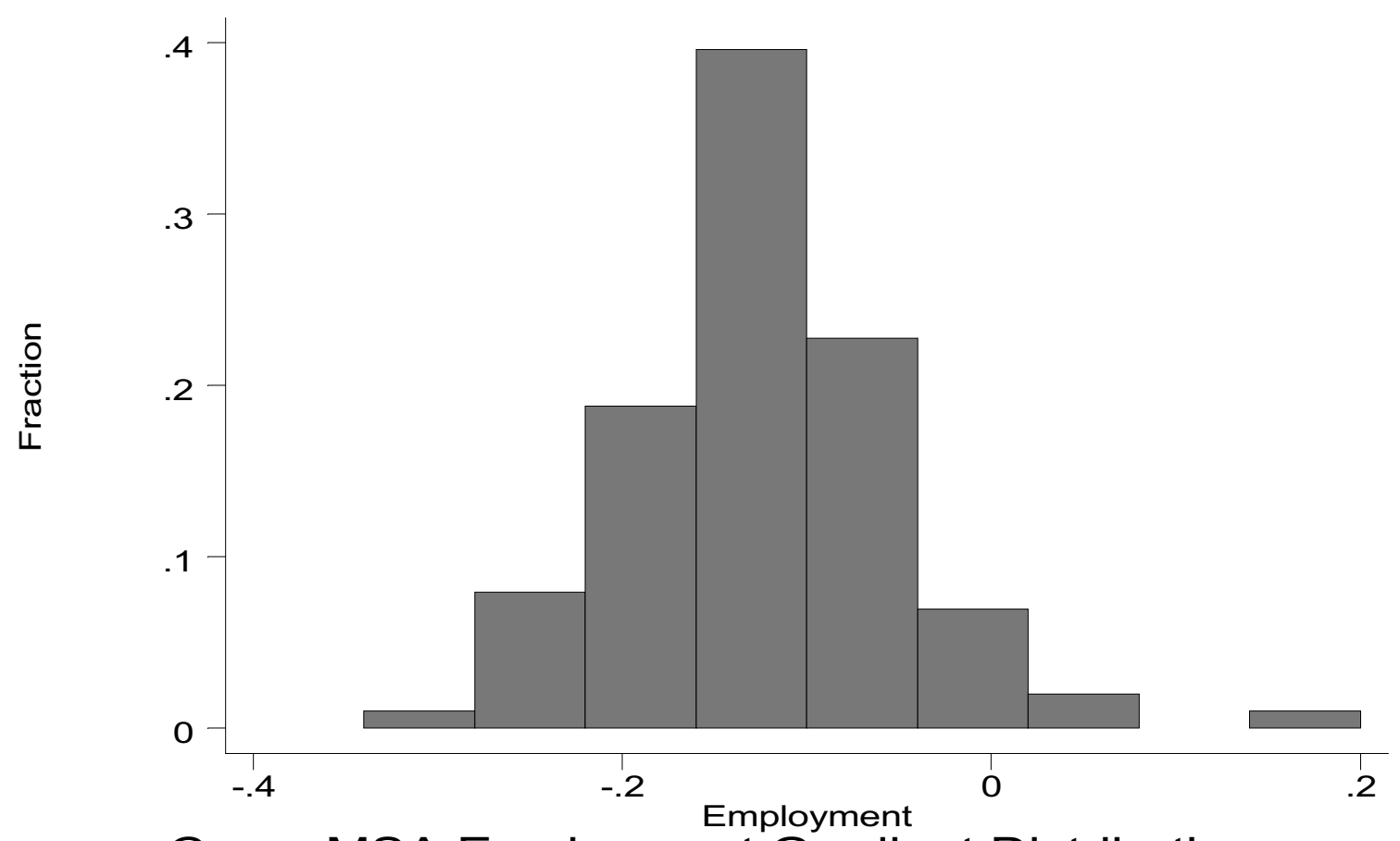

Cross-MSA Employment Gradient Distribution 
Figure 4

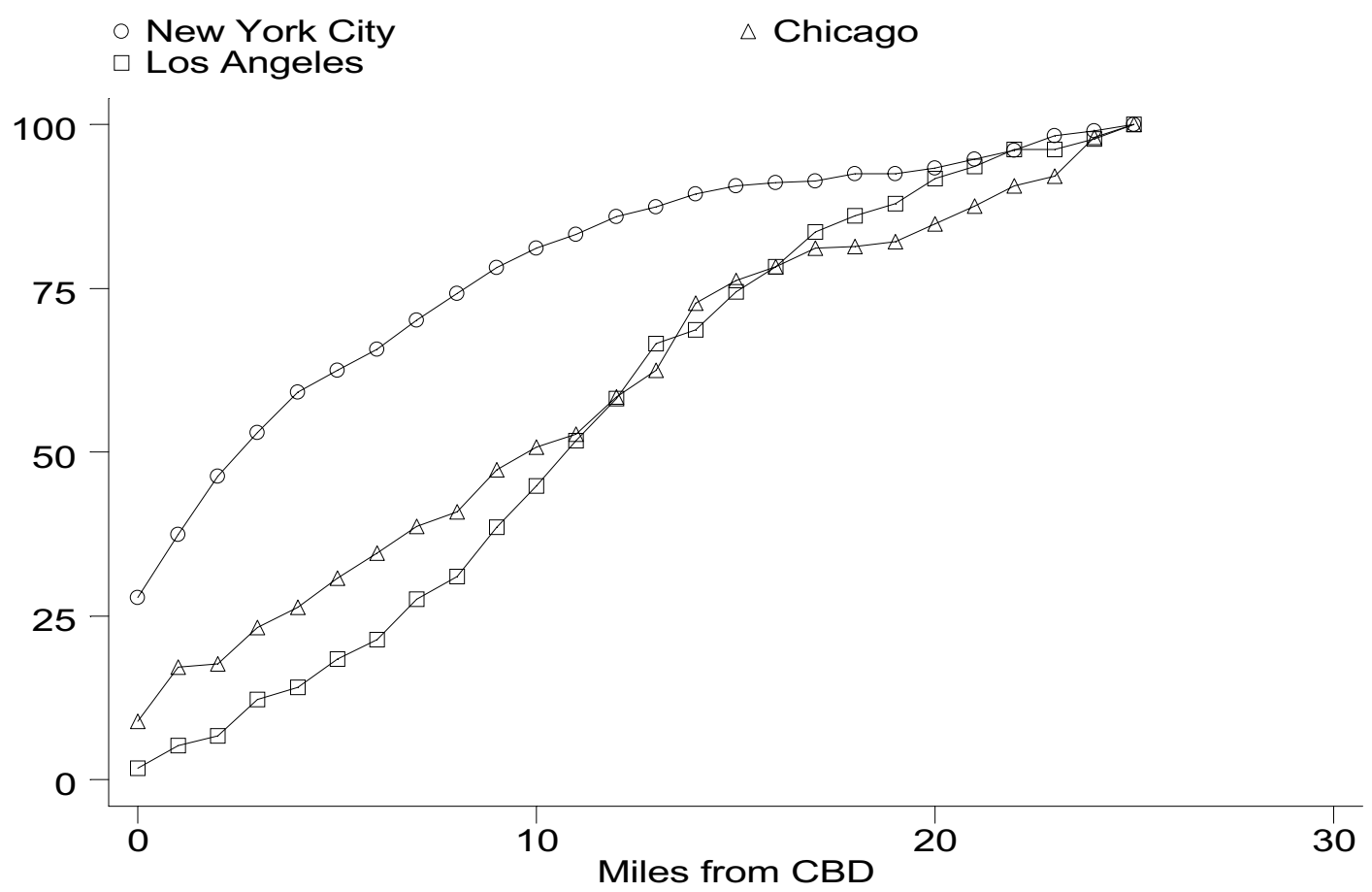

The Distribution of Jobs in Three Major Metro Areas 
Figure 5

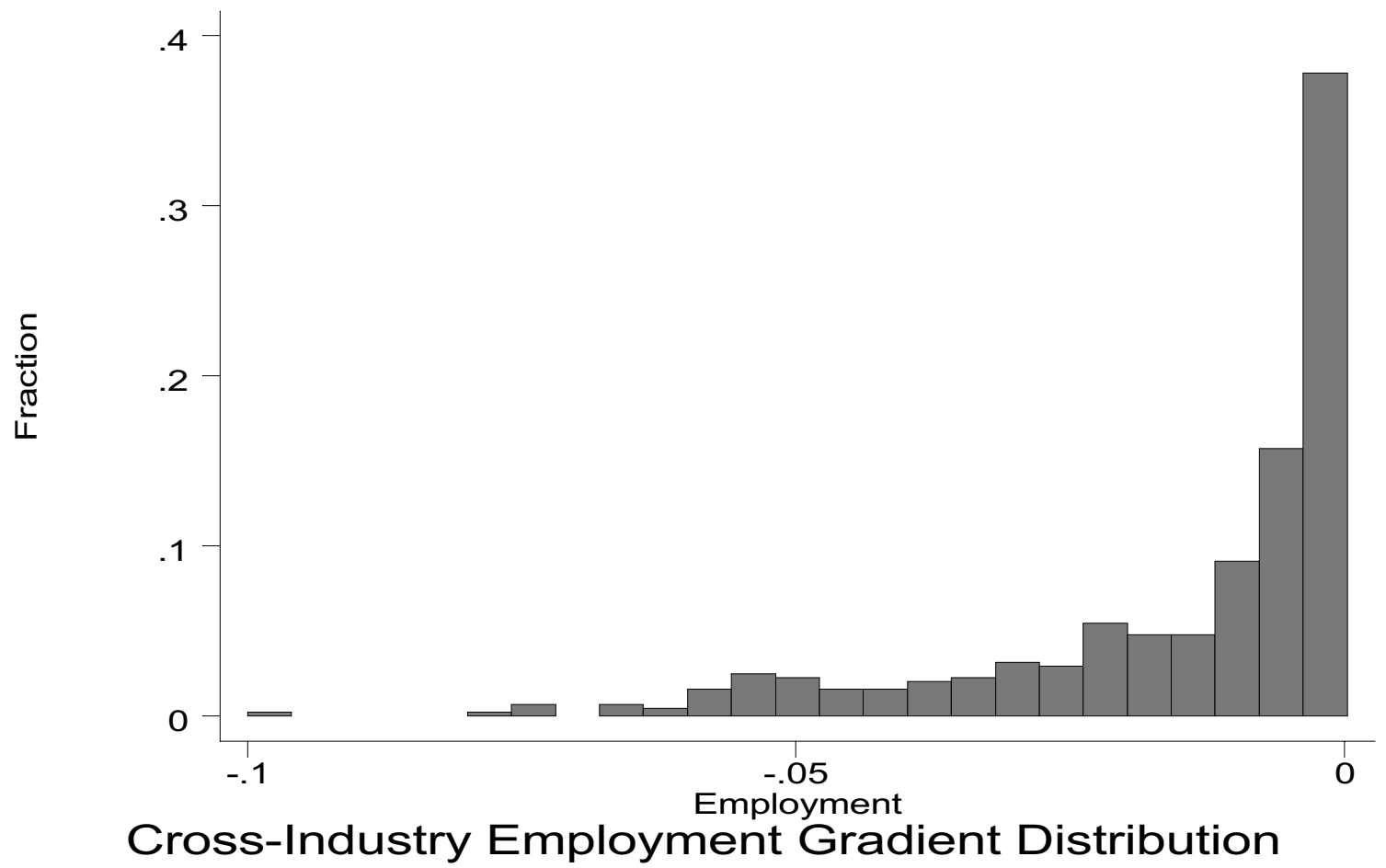


Figure 6

- Commercial Banking

$\triangle$ Carpets and Rugs

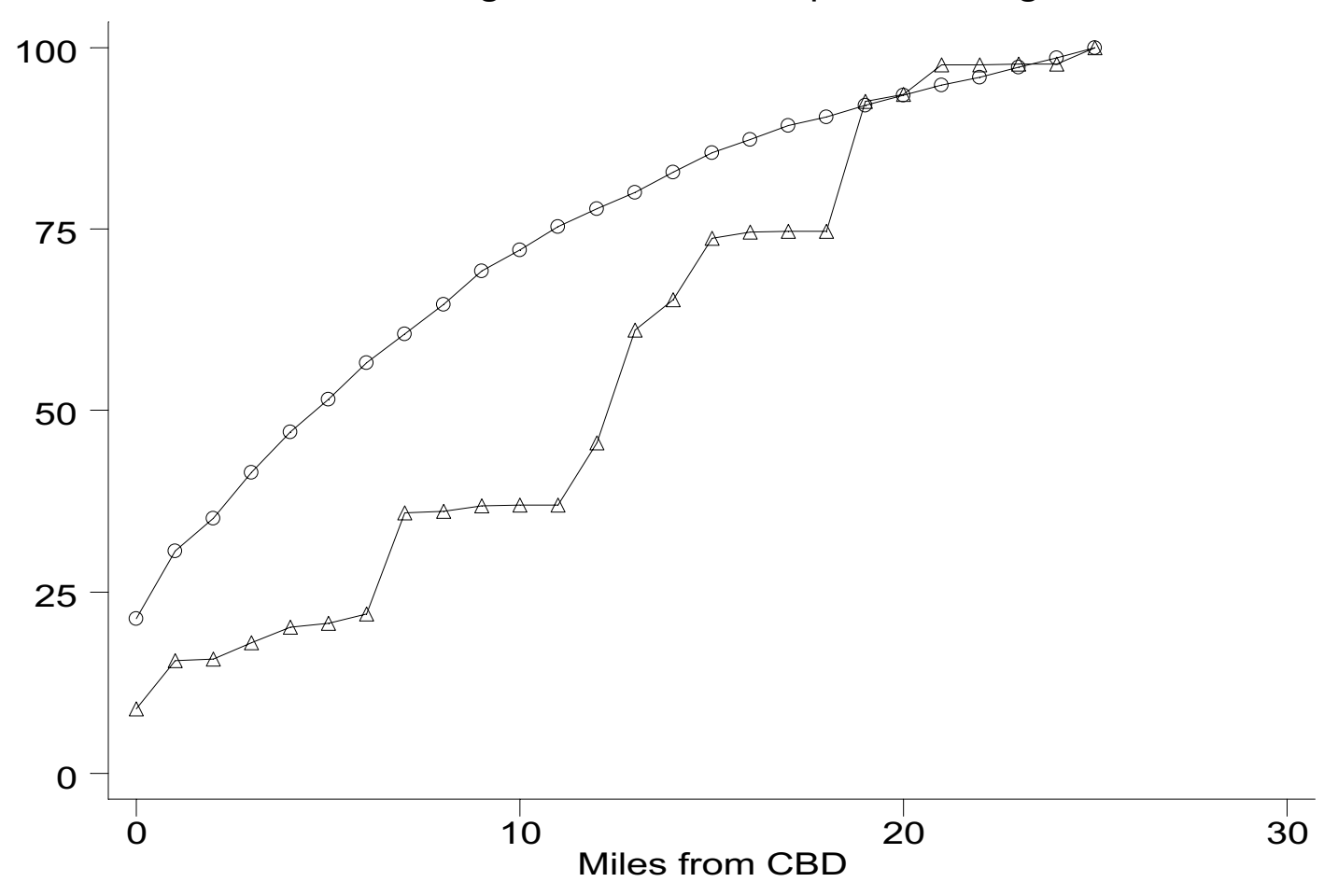


Figure 7

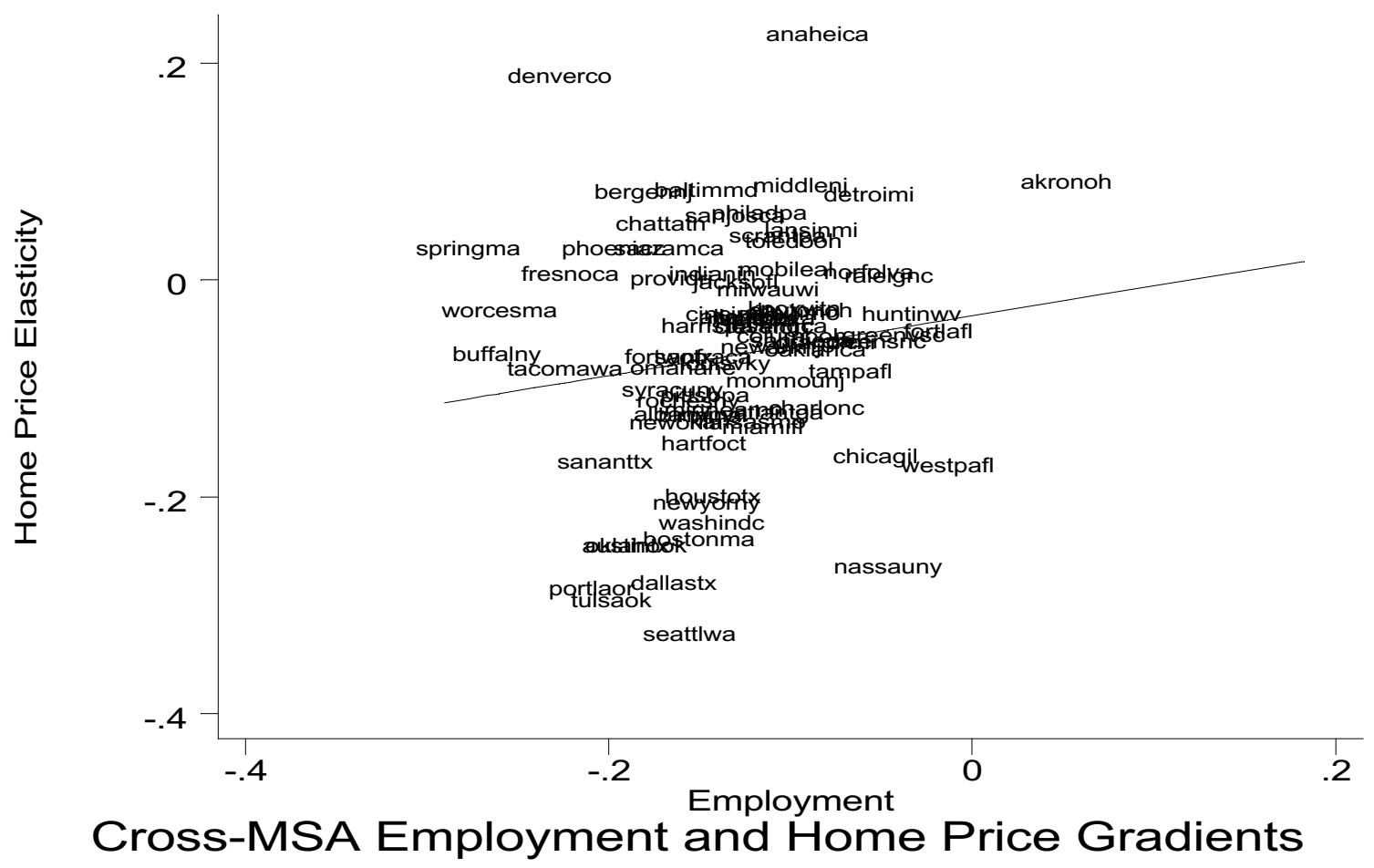




\section{Figure 8}

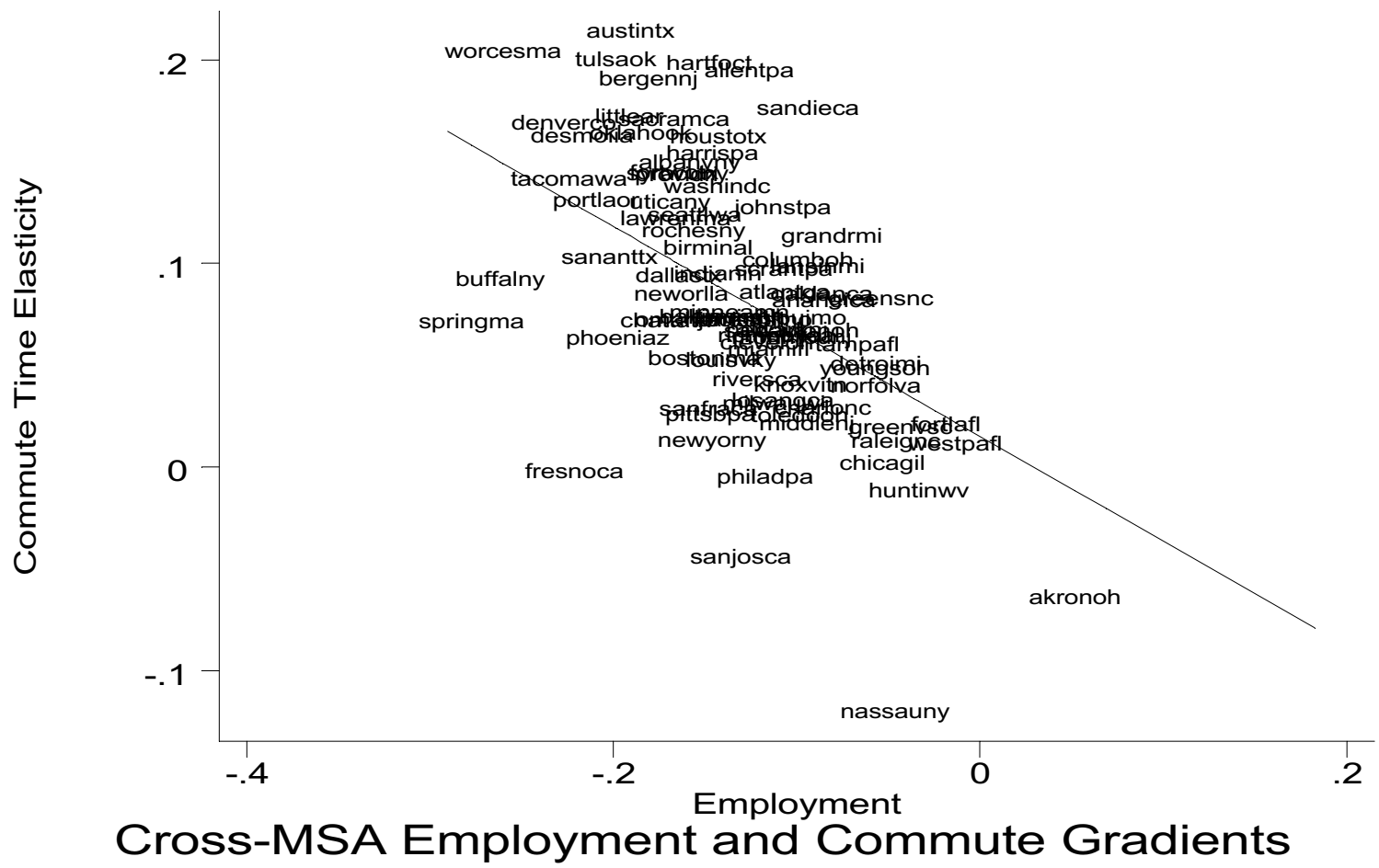




\section{Figure 9}

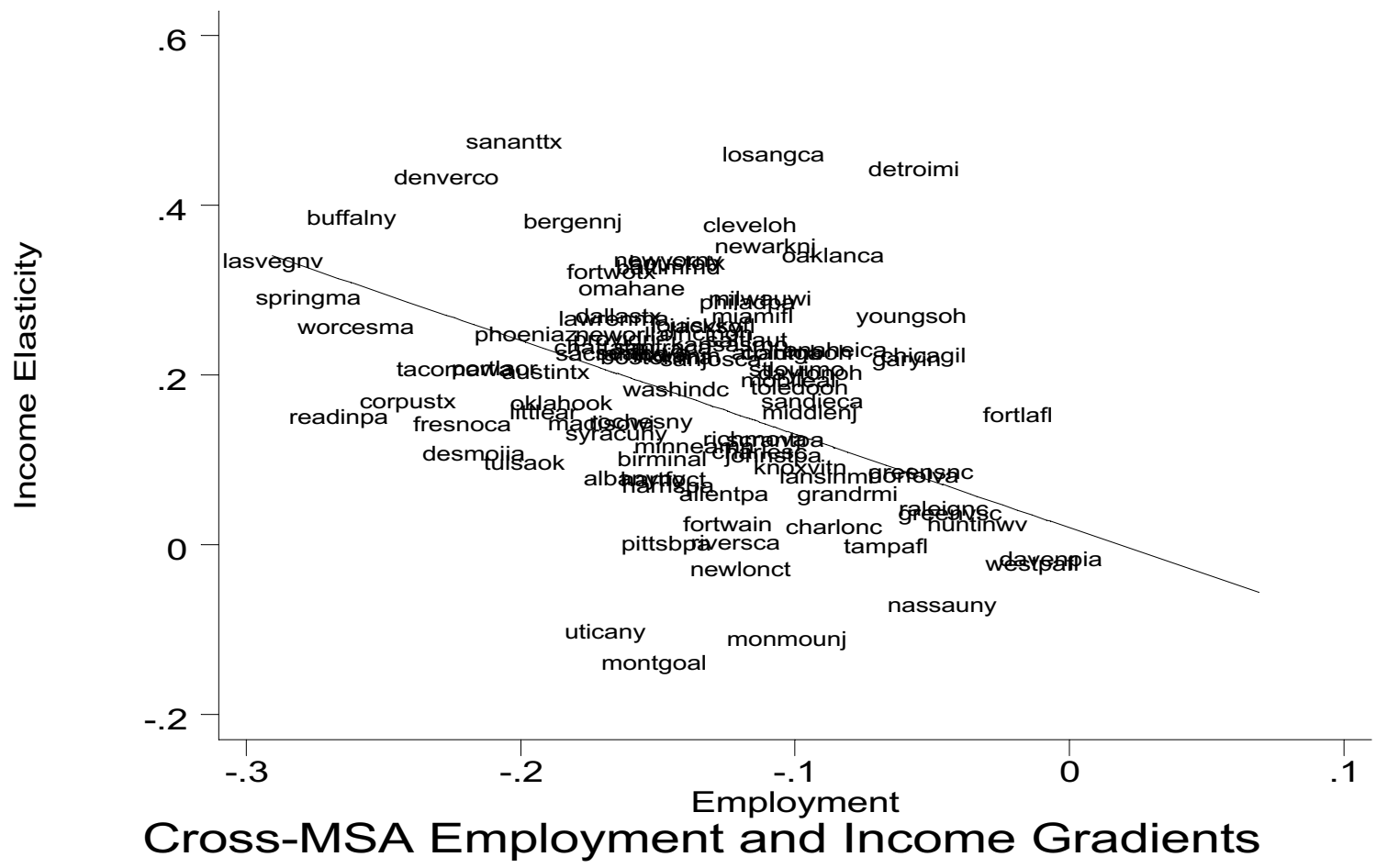


Figure 10

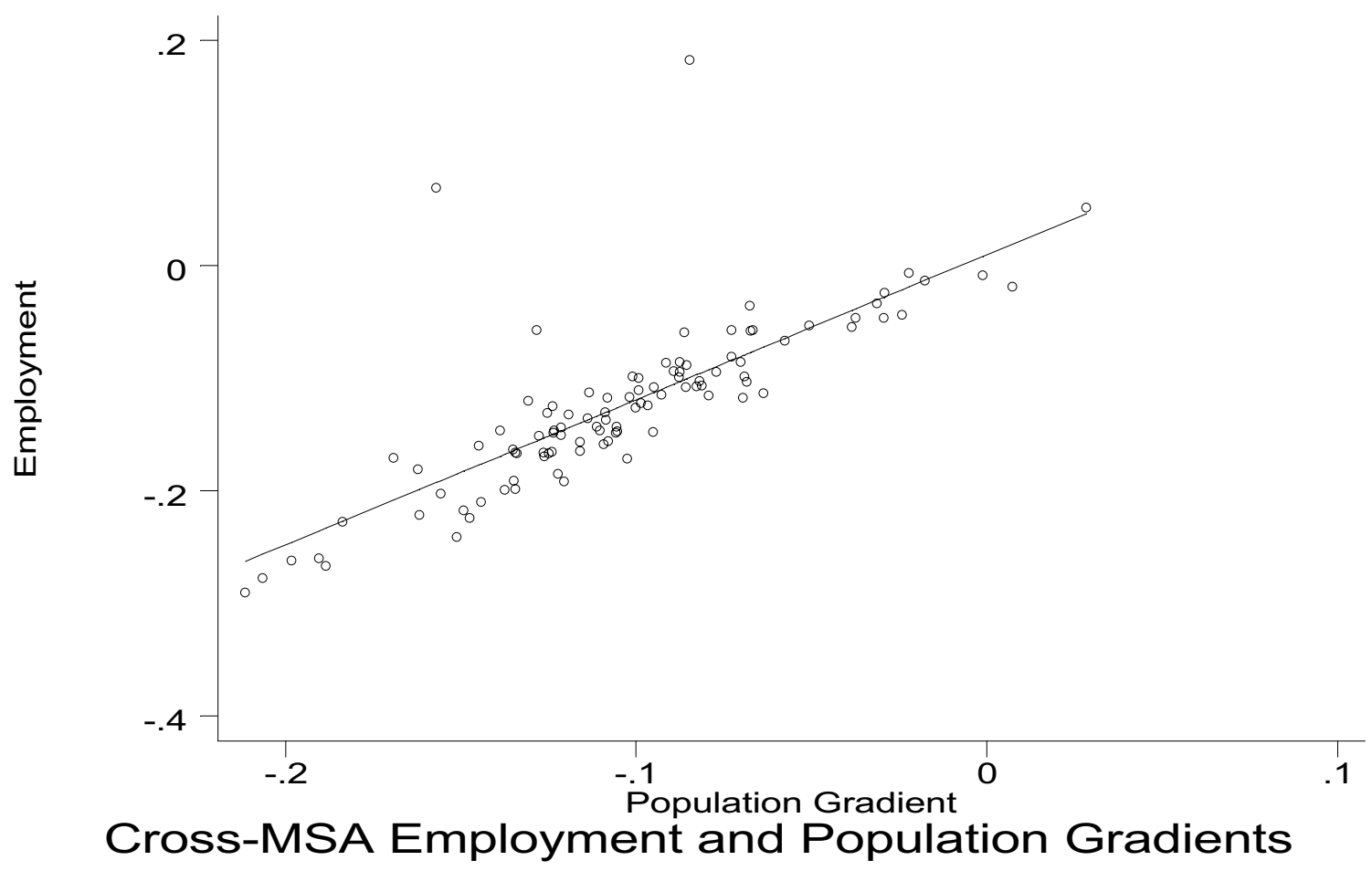




\section{Figure 11}

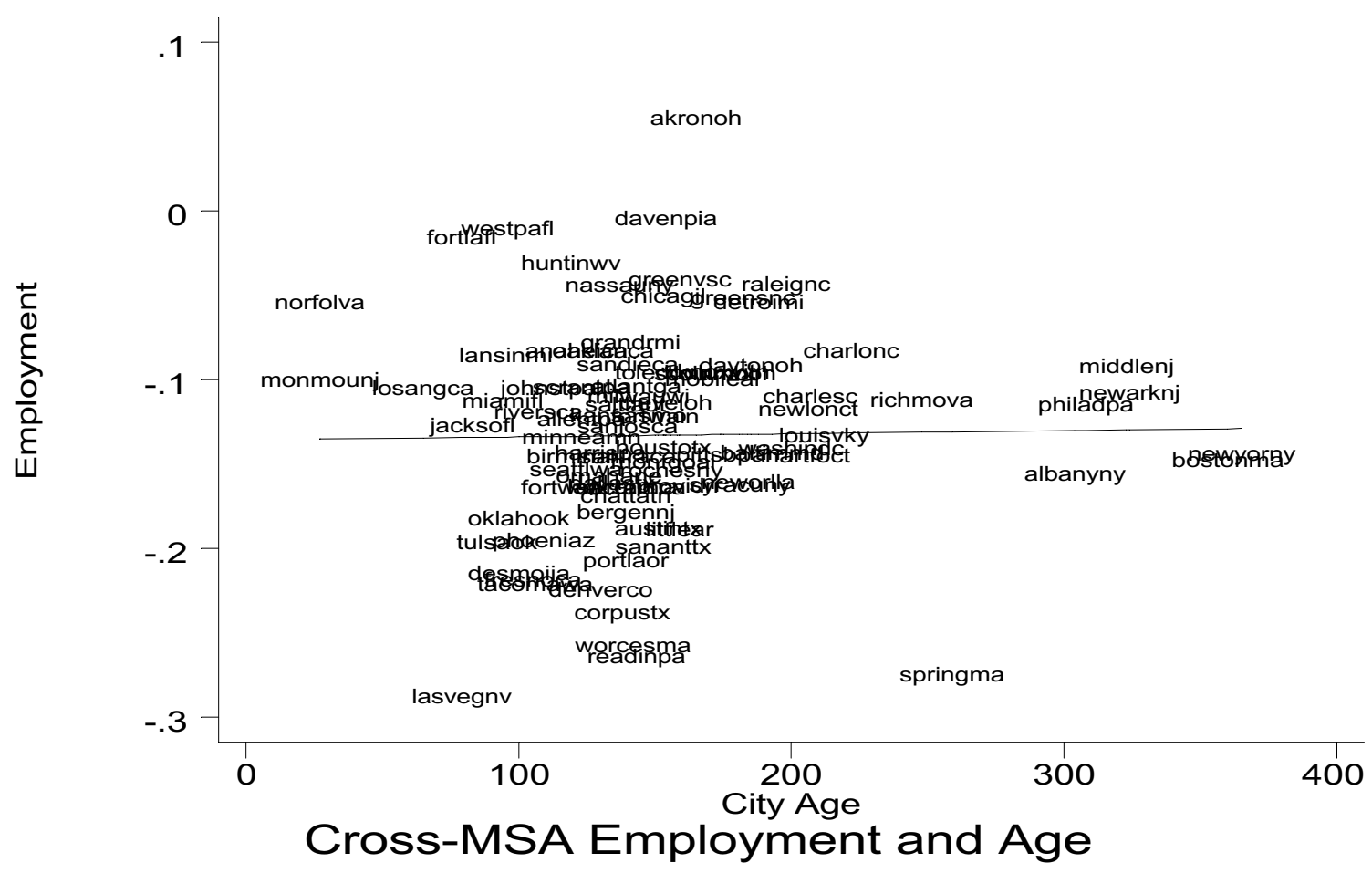


Figure 12

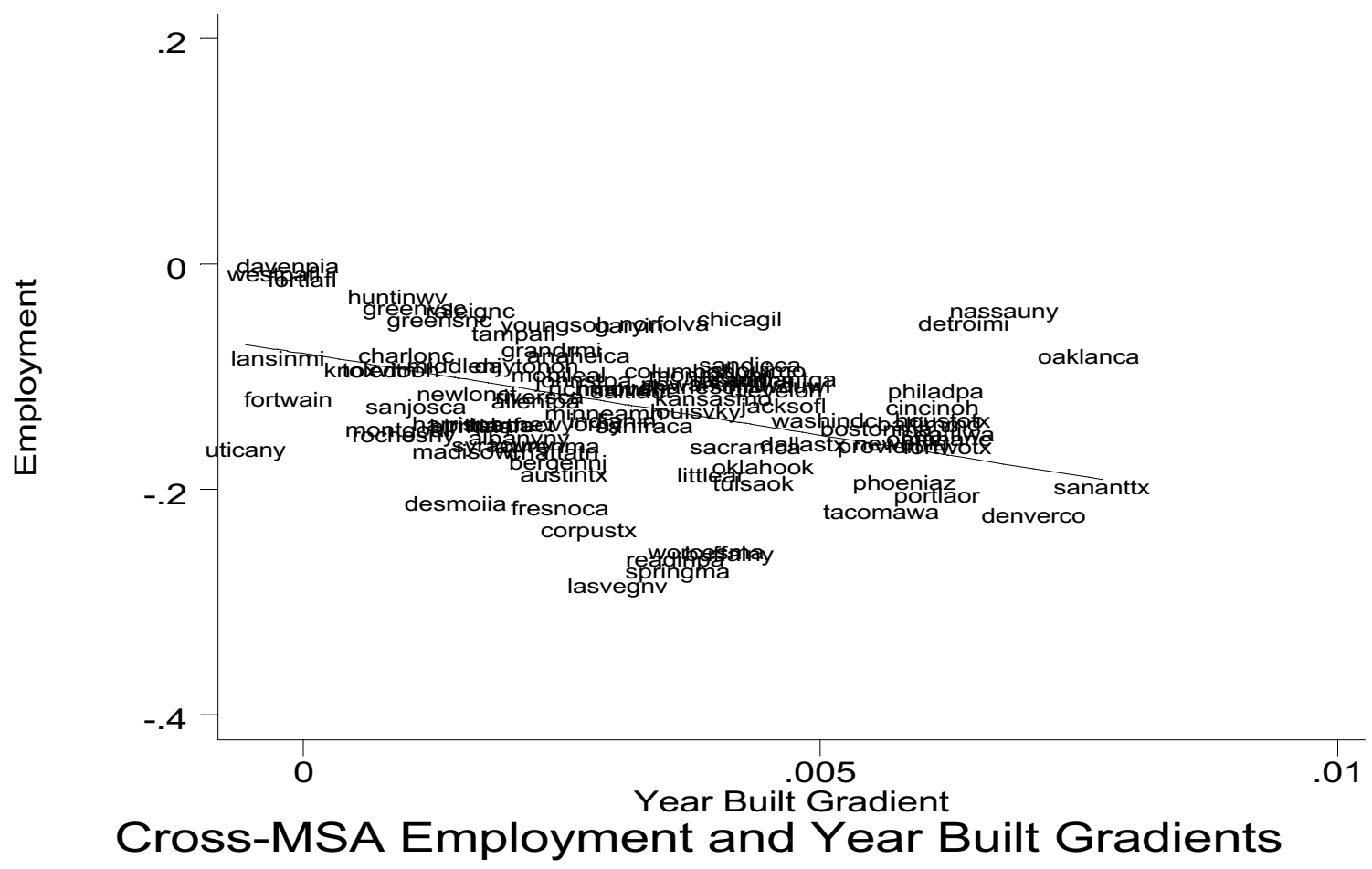


Figure 13

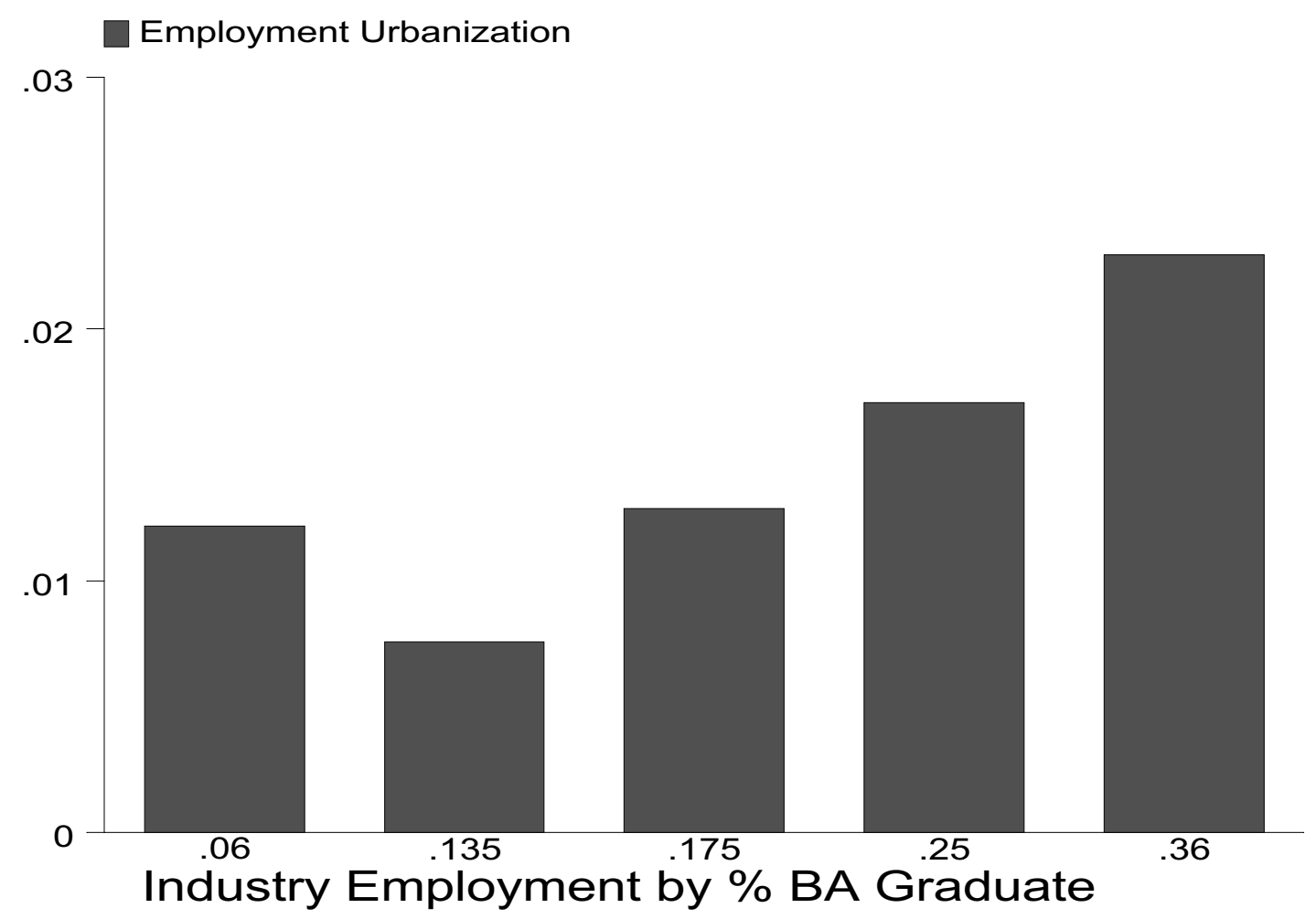


Figure 14

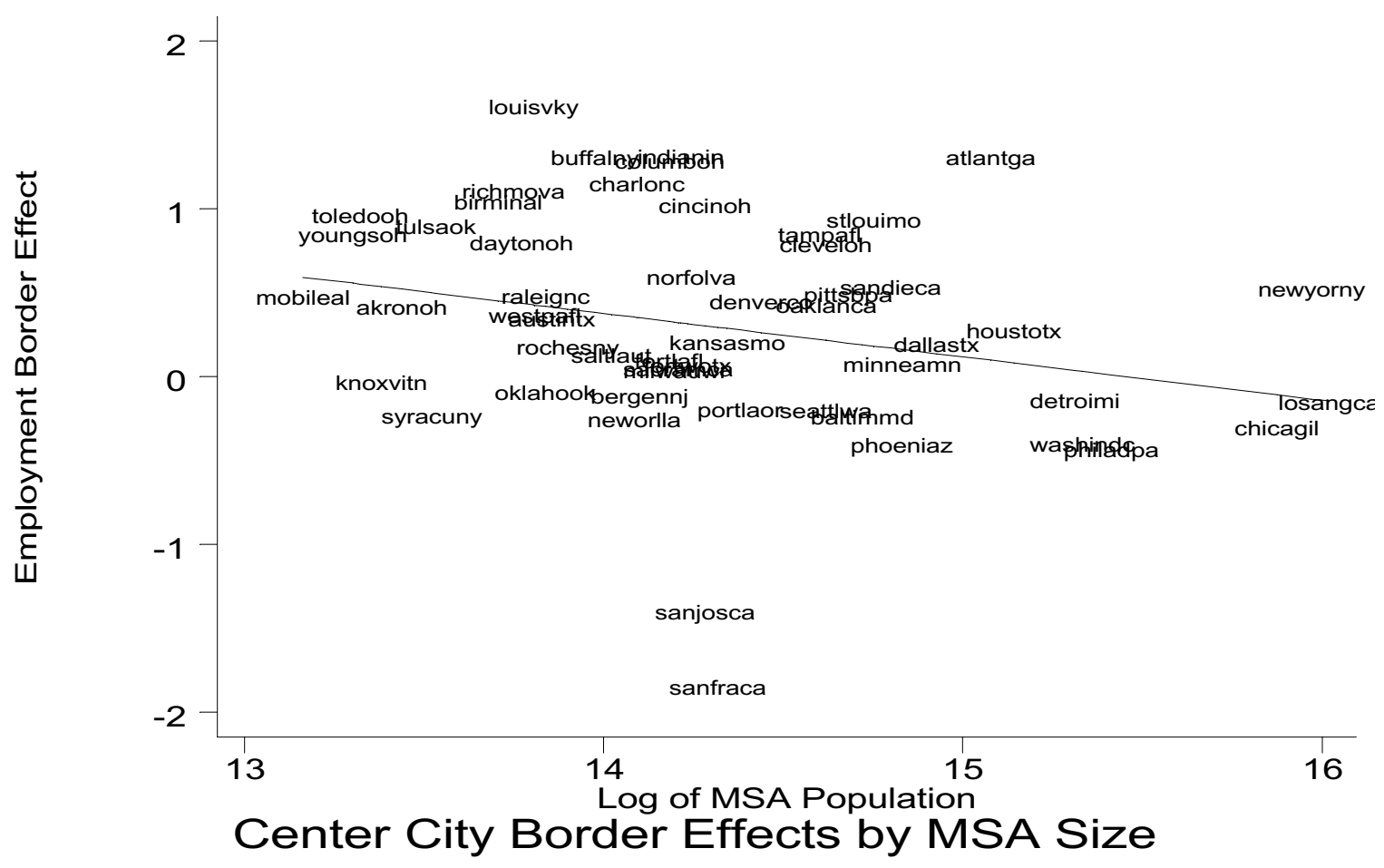




\section{Figure 15}

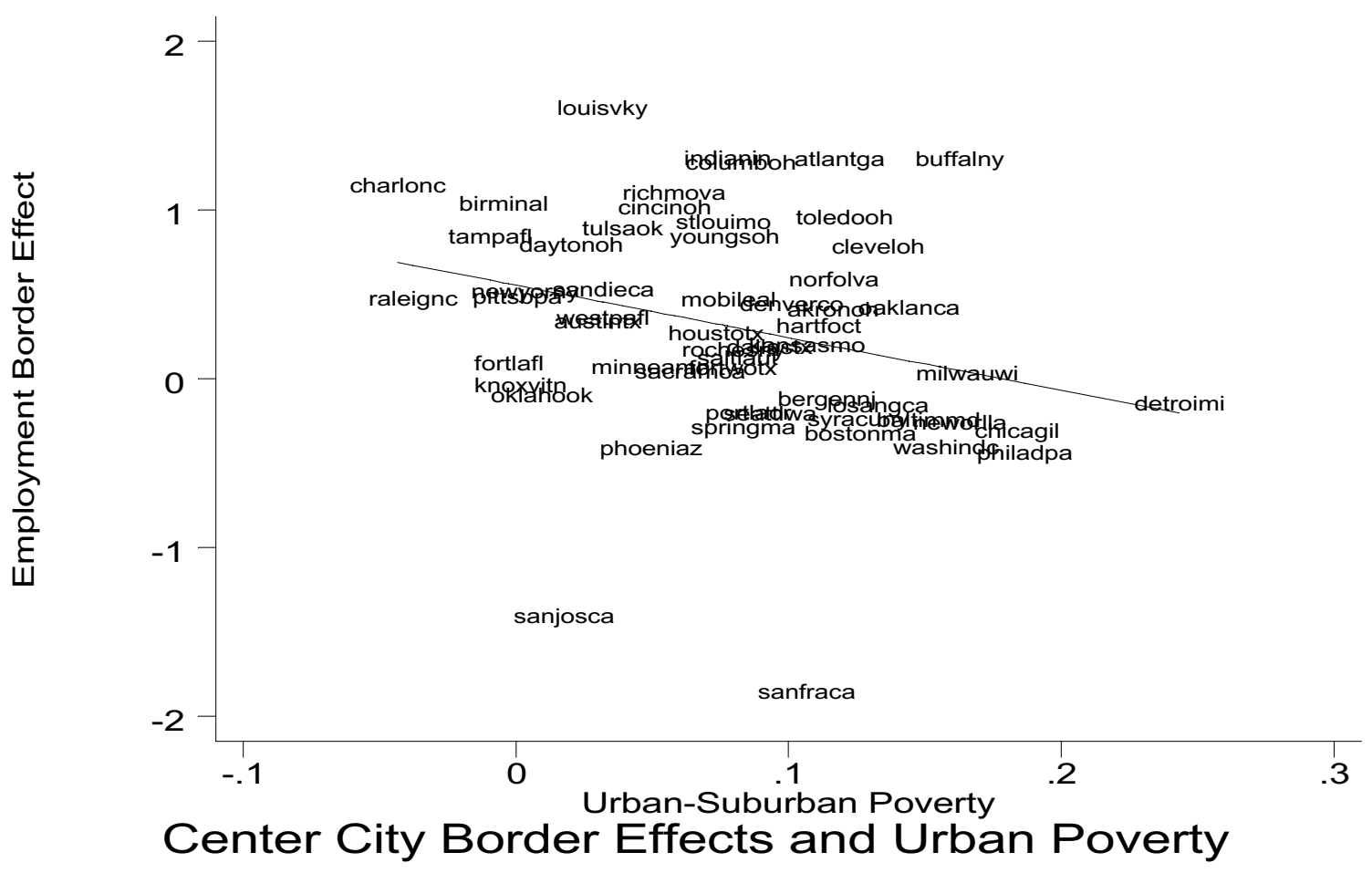


Figure 16

$\square$ Center City Border Effects

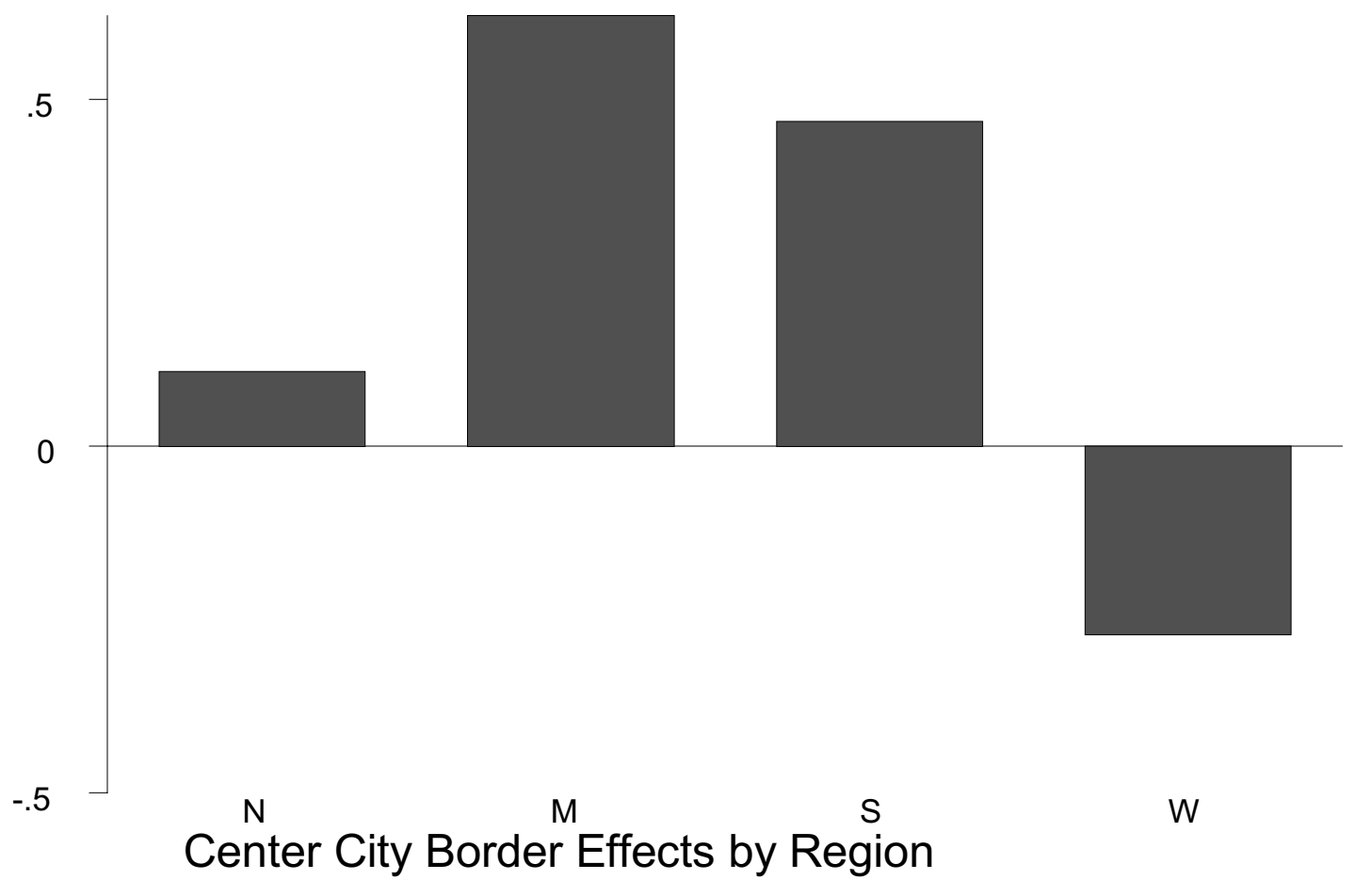

$\mathrm{N}=$ North

$\mathrm{M}=$ Mid-West

$\mathrm{S}=$ South

$\mathrm{W}=\mathrm{West}$ 


\section{MSA Correlations}

$\mathrm{n}=85$

log level slope

three mile share

ten mile share

median distance

log-level slope
three mile share
ten mile share
median distance

1

$-0.447$

$-0.7$

0.64

1
0.559
-0.638

$-0.906$

Table $1 b$

SIC Correlations

$\mathrm{n}=439$

log level slope

three mile share

ten mile share

median distance

log-level slope
three mile share
ten mile share
median distance

$-0.022$

$-0.168$

0.176

0.71

$-0.702$

$-0.885$

In both panels, the log-level slope is the OLS regression coefficient of the log of zip code job density regressed on the the zip code's distance from the CBD. The three mile and ten mile share represent the share of MSA jobs located in these respective rings. Median distance is the distance from the CBD for the median employee. 
Table 2 Regional Trends in Employment Centralization

\begin{tabular}{|c|c|c|c|c|}
\hline & \begin{tabular}{|l} 
East \\
MSA/PMSA
\end{tabular} & Beta & \begin{tabular}{|l} 
South \\
MSA/PMSA
\end{tabular} & Beta \\
\hline \multicolumn{2}{|c|}{ average log-level slope } & \multicolumn{2}{|c|}{-0.151} & -0.126 \\
\hline three mile share & & \multicolumn{2}{|c|}{0.189} & 0.145 \\
\hline ten mile share & & \multicolumn{2}{|c|}{0.616} & 0.561 \\
\hline median distance & & \multicolumn{2}{|c|}{8.029} & 9.383 \\
\hline \multirow{5}{*}{ Five most centralized } & Reading, PA & \multicolumn{2}{|c|}{\begin{tabular}{l|l|l}
-0.267 & Corpus, TX \\
\end{tabular}} & -0.241 \\
\hline & Buffalo, NY & \multirow{2}{*}{\multicolumn{2}{|c|}{\begin{tabular}{l|l}
-0.262 & San Antonio, TX \\
-0.181 & Tulsa, OK
\end{tabular}}} & -0.202 \\
\hline & Bergen, NJ & & & -0.199 \\
\hline & Utica, NY & \multicolumn{2}{|c|}{-0.169 Little Rock, AR } & -0.192 \\
\hline & Syracuse, NY & \multicolumn{2}{|c|}{$-0.165 \mid$ Austin, TX } & -0.191 \\
\hline \multirow[t]{7}{*}{ Five least centralized } & Johnston, PA & \multicolumn{2}{|c|}{\begin{tabular}{l|l|l}
-0.108 & Greensville, NC
\end{tabular}} & -0.054 \\
\hline & Scranton, PA & & Raleigh, NC & -0.046 \\
\hline & Monmouth, NJ & \multicolumn{2}{|c|}{-0.103 Greenville, SC } & -0.044 \\
\hline & Middlesex, NJ & \multicolumn{2}{|c|}{-0.095 Fort Lauderdale, FL } & -0.019 \\
\hline & Nassau, NY & \multicolumn{2}{|c|}{-0.047 West Palm Beach, FL } & -0.014 \\
\hline & Midwest & & |West & \\
\hline & MSA/PMSA & Beta & MSA/PMSA & Beta \\
\hline \multicolumn{2}{|l|}{ average log-level slope } & \multicolumn{2}{|c|}{-0.105} & -0.167 \\
\hline three mile share & & \multicolumn{2}{|c|}{0.150} & 0.174 \\
\hline ten mile share & & \multicolumn{2}{|c|}{0.580} & 0.608 \\
\hline median distance & & \multicolumn{2}{|c|}{8.819} & 8.304 \\
\hline \multirow[t]{5}{*}{ Five most centralized } & Des Moines, IA & \multicolumn{2}{|c|}{$\begin{array}{c}-0.217 \\
\text { Las Vegas, NV }\end{array}$} & -0.291 \\
\hline & Madison, WI & \multirow{2}{*}{\multicolumn{2}{|c|}{\begin{tabular}{l|l}
-0.171 & Denver, CO \\
-0.160 & Tacoma, WA
\end{tabular}}} & -0.227 \\
\hline & Omaha, NE & \multirow{2}{*}{\multicolumn{2}{|c|}{\begin{tabular}{l|l}
-0.160 & Iacoma, WA \\
-0.143 & Fresno, CA
\end{tabular}}} & -0.224 \\
\hline & Indiana, IN & & & -0.221 \\
\hline & Minneapolis, MN & \multicolumn{2}{|c|}{-0.137 Portland, OR } & -0.210 \\
\hline \multirow[t]{5}{*}{ Five least centralized } & Detroit, MI & \multicolumn{2}{|c|}{\begin{tabular}{l|l}
-0.057 & Riverside, CA \\
\end{tabular}} & -0.122 \\
\hline & Chicago, IL & \multirow{2}{*}{\multicolumn{2}{|c|}{\begin{tabular}{l|l}
-0.053 & Salt Lake City, UT \\
-0.034 & Los Angeles, CA
\end{tabular}}} & -0.118 \\
\hline & Huntington, WV & & & -0.108 \\
\hline & Davenport, IA & \multicolumn{2}{|c|}{-0.007 San Diego, CA } & -0.094 \\
\hline & Akron, $\mathrm{OH}$ & \multicolumn{2}{|c|}{0.052 Oakland, CA } & -0.086 \\
\hline
\end{tabular}

For each MSA with over 25 zip codes, an OLS regression is estimated where the dependent variable is a zip code's log(job density) and the independent variable is zip code distance from the CBD.

The OLS slopes are sorted by most and least centralized. 
Table 3 Centralization by Industry

SIC Code Industry Name

Beta

\begin{tabular}{l|r|l|r|}
\hline Ten most centralized & 581 & Eating and drinking places * & -0.099 \\
& 541 & Grocery stores & -0.077 \\
& 801 & Offices and clinics of medical doctors & -0.075 \\
& 738 & Miscellaneous business services * & -0.075 \\
& 866 & Religious organizations & -0.074 \\
& 832 & Individual and family services & -0.067 \\
& 736 & Personnel supply services * & -0.065 \\
& 602 & Commercial banks & -0.065 \\
& 651 & Real estate operators and lessors & -0.063 \\
& 653 & Real estate agents and managers & -0.060 \\
\hline Ten least centralized & 124 & Coal mining services & 0.000 \\
& 140 & Nonmetallic minerals, except fuels * & 0.000 \\
& 214 & Tobacco stemming and redrying & 0.000 \\
& 460 & Pipelines, except natural gas * & 0.000 \\
& 101 & Iron ores & 0.000 \\
& 840 & Museums, botanical, zoological gardens * & 0.000 \\
& 376 & Guided missiles, space vehicles, parts * & 0.000 \\
& 213 & Chewing and smoking tobacco & 0.000 \\
& 147 & Chemical and fertilizer minerals * & 0.000 \\
& 142 & Crushed and broken stone * & 0.000 \\
\hline \hline
\end{tabular}

For each three digit SIC industry, a OLS regression is estimated. The unit of analysis is the zip code. The dependent variable is $\log (1+$ job density $)$ and the independent variables are MSA fixed effects and the zip code's distance from the CBD. This table reports the coefficient on zip code distance. 
Table 4 Travel Time, Speed and Distance

\begin{tabular}{l|c|c|c|} 
Dependent variable & Log(travel speed) & Log(travel time) & Log(travel distance) \\
\hline \multirow{2}{*}{ Log(density) } & -0.1100 & -0.0457 & -0.1557 \\
& $(0.0031)$ & $(0.0038)$ & $(0.0055)$ \\
R2 & 0.0948 & 0.0441 & 0.0566 \\
$\mathrm{~N}$ & 22162 & 22162 & 22162 \\
\hline \hline
\end{tabular}

The data source is the 1995 National Personal Transportation Survey.

For households who live in a metropolitan area, this table reports how the

population density at place of residence (based on the census block) affects

travel time to work and travel speed. Metropolitan area fixed effects

are included in each OLS regression. Standard errors reported in

parentheses. Intercepts calculated but not shown. 
Table 5 Distribution of Population and Jobs

MSA

Inner Ring

Outer Ring

Employment Population Employment Population

\begin{tabular}{|c|c|c|c|c|}
\hline & & & & \\
\hline Albany, NY & 0.5048 & 0.2935 & 0.1211 & 0.1037 \\
\hline Atlanta, GA & 0.4278 & 0.2181 & 0.2116 & 0.1330 \\
\hline Baltimore, MD & 0.3816 & 0.3063 & 0.1155 & 0.0875 \\
\hline Bergen, NJ & 0.1654 & 0.1189 & 0.1396 & 0.0752 \\
\hline Birmingham, AL & 0.6716 & 0.4050 & 0.0954 & 0.1043 \\
\hline Boston, MA & 0.4331 & 0.2979 & 0.0976 & 0.0575 \\
\hline Chicago, IL & 0.2969 & 0.1762 & 0.1285 & 0.0622 \\
\hline Cincinatti, $\mathrm{OH}$ & 0.4147 & 0.2925 & 0.2427 & 0.1157 \\
\hline Cleveland, $\mathrm{OH}$ & 0.3223 & 0.2062 & 0.1237 & 0.0880 \\
\hline Dallas, TX & 0.5496 & 0.2716 & 0.1736 & 0.1549 \\
\hline Denver, CO & 0.4857 & 0.2965 & 0.2133 & 0.1470 \\
\hline Detroit, MI & 0.3392 & 0.2099 & 0.2452 & 0.1193 \\
\hline Houston, TX & 0.4722 & 0.2328 & 0.1550 & 0.1019 \\
\hline Kansas, MO & 0.5052 & 0.3250 & 0.2248 & 0.2098 \\
\hline Los Angeles, CA & 0.3236 & 0.1579 & 0.1994 & 0.1136 \\
\hline Minneapolis, MN & 0.5612 & 0.3375 & 0.1499 & 0.1635 \\
\hline Nassau NY & 0.1299 & 0.0571 & 0.1048 & 0.0425 \\
\hline New York, NY & 0.5986 & 0.2702 & 0.0632 & 0.0882 \\
\hline Newark, NJ & 0.2423 & 0.1940 & 0.1403 & 0.0364 \\
\hline Oakland, CA & 0.2562 & 0.1999 & 0.1964 & 0.0539 \\
\hline Philadelphia, PA & 0.3190 & 0.3029 & 0.1822 & 0.0930 \\
\hline Phoenix, AZ & 0.3952 & 0.1864 & 0.1610 & 0.1598 \\
\hline Pittsburgh, PA & 0.4552 & 0.2636 & 0.0431 & 0.0373 \\
\hline Riverside, CA & 0.3501 & 0.1904 & 0.1600 & 0.1311 \\
\hline Sacramento, CA & 0.5249 & 0.3517 & 0.1044 & 0.1467 \\
\hline St. Louis, MO & 0.4714 & 0.3339 & 0.2182 & 0.1552 \\
\hline San Diego, CA & 0.3997 & 0.2167 & 0.2296 & 0.1075 \\
\hline San Francisco, CA & 0.5552 & 0.3872 & 0.1596 & 0.1319 \\
\hline Seattle, WA & 0.5463 & 0.2558 & 0.1715 & 0.1365 \\
\hline Tampa, FL & 0.3614 & 0.1999 & 0.2609 & 0.1458 \\
\hline Washington, DC & 0.4578 & 0.2495 & 0.2047 & 0.1004 \\
\hline
\end{tabular}

The Inner Ring is defined as those zip codes whose distance from the CBD is less than the MSA median. The Outer Ring is defined as those zip codes whose distance from the CBD is greater than the MSA median. In each ring, zip codes are sorted by job density from highest density to lowest.

Zip codes are added until the total land area of the set equals 5\% of the MSA's total area.

The table reports the share of all MSA jobs and population in each of these cells. 
Table 6 Centralization of Employment not Explained by Centralization of Population

\begin{tabular}{|c|c|c|c|c|c|}
\hline & MSA/PMSA & MSA & $\begin{array}{l}\text { "Unexplained" } \\
\text { Employment } \\
\text { Centralization }\end{array}$ & $\begin{array}{c}\text { Employment } \\
\text { Centralization } \\
\text { log-level slope }\end{array}$ & $\begin{array}{c}\text { Population } \\
\text { Centralization } \\
\text { log-level slope }\end{array}$ \\
\hline \multirow[t]{4}{*}{ Top five } & Chattanooga, TN & 1560 & -0.0475 & -0.1722 & -0.1025 \\
\hline & Charleston, NC & 1440 & -0.0472 & -0.1258 & -0.0636 \\
\hline & Salt Lake City, UT & 7160 & -0.0331 & -0.1185 & -0.0694 \\
\hline & Little Rock, AR & 4400 & -0.0324 & -0.1783 & -0.1204 \\
\hline \multirow{3}{*}{ Bottom five } & Gary, IN & 2960 & 0.0346 & -0.0706 & -0.0861 \\
\hline & New London, CT & 5520 & 0.0385 & -0.1194 & -0.1306 \\
\hline & Las Vegas, NV & 4120 & 0.0394 & -0.2143 & -0.2114 \\
\hline
\end{tabular}

For each MSA, two regressions are estimated. The first regression fits $\log (j o b$ density) as a function of zip code distance from the CBD. The second regression fits log(population density) as a function of zip code distance from the CBD. In the second stage regression, the OLS slope from the employment regression is regressed on the OLS slope from the population regression.

This table reports the residual from this regression. 
Table 7 Explaining MSA Employment Concentration

Dependent Variable

Log-level employment slope Share of MSA jobs outside of the inner three mile ring

\begin{tabular}{|c|c|c|c|c|c|c|}
\hline & (1) & (2) & (3) & (4) & (5) & (6) \\
\hline Midwest & $\begin{array}{c}0.0426 \\
(0.0165)\end{array}$ & $\begin{array}{c}0.0647 \\
(0.0213)\end{array}$ & $\begin{array}{c}0.0539 \\
(0.0207)\end{array}$ & $\begin{array}{c}0.0352 \\
(0.0344)\end{array}$ & $\begin{array}{c}0.0501 \\
(0.0379)\end{array}$ & $\begin{array}{c}0.0058 \\
(0.0343)\end{array}$ \\
\hline South & $\begin{array}{c}0.0211 \\
(0.0170)\end{array}$ & $\begin{array}{c}0.0289 \\
(0.0197)\end{array}$ & $\begin{array}{c}0.0235 \\
(0.0189)\end{array}$ & $\begin{array}{c}0.0329 \\
(0.0310)\end{array}$ & $\begin{array}{c}0.0688 \\
(0.0432)\end{array}$ & $\begin{array}{c}0.0465 \\
(0.0364)\end{array}$ \\
\hline West & $\begin{array}{l}-0.0261 \\
(0.0177)\end{array}$ & $\begin{array}{c}0.0218 \\
(0.0200)\end{array}$ & $\begin{array}{c}0.0169 \\
(0.0193)\end{array}$ & $\begin{array}{l}-0.0125 \\
(0.0384)\end{array}$ & $\begin{array}{c}0.0148 \\
(0.0418)\end{array}$ & $\begin{array}{c}-0.0053 \\
(0.0366)\end{array}$ \\
\hline $\log (\mathrm{MSA}$ area) & $\begin{array}{l}-0.0121 \\
(0.0065)\end{array}$ & $\begin{array}{c}-0.0046 \\
(0.0056)\end{array}$ & $\begin{array}{c}-0.0030 \\
(0.0049)\end{array}$ & $\begin{array}{c}0.0115 \\
(0.0185)\end{array}$ & $\begin{array}{c}0.0087 \\
(0.0143)\end{array}$ & $\begin{array}{c}0.0154 \\
(0.0120)\end{array}$ \\
\hline log(major city's age) & $\begin{array}{l}-0.0051 \\
(0.0129)\end{array}$ & $\begin{array}{c}-0.0121 \\
(0.0128)\end{array}$ & $\begin{array}{c}-0.0109 \\
(0.0125)\end{array}$ & $\begin{array}{c}-0.0377 \\
(0.0257)\end{array}$ & $\begin{array}{c}-0.0258 \\
(0.0290)\end{array}$ & $\begin{array}{l}-0.0211 \\
(0.0243)\end{array}$ \\
\hline $\log ($ MSA Population) & $\begin{array}{c}0.0182 \\
(0.0085)\end{array}$ & $\begin{array}{c}0.0152 \\
(0.0097)\end{array}$ & $\begin{array}{c}-0.0013 \\
(0.0134)\end{array}$ & $\begin{array}{c}0.0248 \\
(0.0190)\end{array}$ & $\begin{array}{c}0.0531 \\
(0.0212)\end{array}$ & $\begin{array}{l}-0.0150 \\
(0.0292)\end{array}$ \\
\hline Percent Hispanic & & $\begin{array}{c}-0.0004 \\
(0.0005)\end{array}$ & $\begin{array}{c}-0.0003 \\
(0.0005)\end{array}$ & & $\begin{array}{c}-0.0010 \\
(0.0008)\end{array}$ & $\begin{array}{c}-0.0007 \\
(0.0007)\end{array}$ \\
\hline Percent with college or higher degree & & $\begin{array}{c}0.0040 \\
(0.0013)\end{array}$ & $\begin{array}{c}0.0036 \\
(0.0013)\end{array}$ & & $\begin{array}{c}-0.0008 \\
(0.0034)\end{array}$ & $\begin{array}{c}-0.0023 \\
(0.0031)\end{array}$ \\
\hline Percent over 65 years old & & $\begin{array}{c}0.0096 \\
(0.0020)\end{array}$ & $\begin{array}{c}0.0087 \\
(0.0021)\end{array}$ & & $\begin{array}{c}0.0014 \\
(0.0035)\end{array}$ & $\begin{array}{c}-0.0022 \\
(0.0037)\end{array}$ \\
\hline Percent Black & & $\begin{array}{c}0.0019 \\
(0.0009)\end{array}$ & $\begin{array}{c}0.0021 \\
(0.0009)\end{array}$ & & $\begin{array}{c}0.0018 \\
(0.0016)\end{array}$ & $\begin{array}{l}-0.0011 \\
(0.0016)\end{array}$ \\
\hline Share of employment in manufacturing & & $\begin{array}{c}0.3269 \\
(0.2222)\end{array}$ & $\begin{array}{c}0.3284 \\
(0.2093)\end{array}$ & & $\begin{array}{c}0.1387 \\
(0.3929)\end{array}$ & $\begin{array}{c}0.1449 \\
(0.3642)\end{array}$ \\
\hline Share of employment in service & & $\begin{array}{c}-0.5751 \\
(0.1742)\end{array}$ & $\begin{array}{l}-0.5785 \\
(0.1495)\end{array}$ & & $\begin{array}{c}0.7759 \\
(0.3495)\end{array}$ & $\begin{array}{c}0.7897 \\
(0.3098)\end{array}$ \\
\hline log(number of political jurisdictions) & & & $\begin{array}{c}0.0154 \\
(0.0103)\end{array}$ & & & $\begin{array}{c}0.0633 \\
(0.0193)\end{array}$ \\
\hline $\begin{array}{l}\mathrm{R} 2 \\
\mathrm{~N}\end{array}$ & $\begin{array}{c}0.2077 \\
77\end{array}$ & $\begin{array}{c}0.4753 \\
77\end{array}$ & $\begin{array}{c}0.4948 \\
77\end{array}$ & $\begin{array}{c}0.1150 \\
77\end{array}$ & $\begin{array}{c}0.2405 \\
77\end{array}$ & $\begin{array}{c}0.3603 \\
77\end{array}$ \\
\hline
\end{tabular}

The unit of analysis is the metropolitan area. The dependent variables in Columns (1)-(3) is the MSA's OLS slope from a log-level job density on zip code distance from the CBD. The dependent variable in Columns (4)-(6) is the MSA's share of jobs outside of the inner three mile ring. Intercepts calculated but not shown. 
Table 8a Explaining Industry Employment Concentration

Dependent variable: Three Digit SIC industry log-level Urbanization Coefficient

Sample

Worker suburbanization index

Input Supplier Suburbanization Index

Manufacturing

Log of average firm size (workers/plants)

Percent with high school degree

Percent with college or higher degree

Percent of industry workers using computers at their job

Dollar value added per pound of output

Share of domestic production that is exported

Energy expenditure per dollar of output R2

Number of clusters Number of observations

Standard errors reported in parentheses. Intercepts calculated but not shown.

Results reported are for regression with correction for correlation in error structure within two-digit SIC codes.

\begin{tabular}{c|c|c|c|} 
Manufacturing only \\
$(4)$ & $(5)$
\end{tabular}

Whole Sample

(1)

(2)

(3)

0.0955

$(0.0601)$

0.0778

0.0986

(0.0321)

$(0.0324)$

0.0130

(0.0029)

0.0114

(0.0030)

$-0.0019$

$(0.0010)$

$-0.0016$

(0.0009)

(0.0651)

0.1035

(0.0341)

0.0126

(0.0029)

$-0.0019$

(0.0010)

$-0.0126$

(0.0176)

$-0.0230$

(0.0128)

$-0.000000107$

$(0.000000673)$

(5)

\begin{tabular}{l|l}
-0.0381 & -0.0437
\end{tabular}

$\begin{array}{ll}0.0021 & 0.0023\end{array}$

$\begin{array}{ll}(0.0008) & (0.0009)\end{array}$

0.0000527

(6)

(6)

(7)

(7)

$-0.0134$

(0.0181)

(0.0183)

$-0.0454$

$-0.0360$

$(0.0289) \quad(0.0353)$

(0.0357)

(0.035)

0.0019

0.0023

(0.0009)

$(0.0007)$

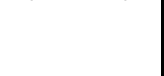

0.0032

$(0.0011)$

0.0033

$(0.0011)$

0.0007

$-0.0002$

$(0.0008)$

\begin{tabular}{c|c|c|c|c|c|c} 
& & & & & $(0.0005)$ & $(0.0008)$ \\
\hline 0.2352 & 0.2487 & 0.2367 & 0.1080 & 0.2150 & 0.1603 & 0.1828 \\
69 & 69 & 65 & 20 & 20 & 20 & 20 \\
434 & 434 & 416 & 123 & 137 & 137 & 120 \\
\hline
\end{tabular}


Table 8b Explaining Industry Employment Concentration

Dependent variable: Share of Three Digit SIC Industries Located Outside the Inner Three Mile Ring

\begin{tabular}{|c|c|c|c|c|c|c|c|}
\hline Sample & Whole sam & & & Manufactu & ng only & & \\
\hline & (1) & (2) & (3) & $(4)$ & (5) & (6) & (7) \\
\hline Worker suburbanization index & $\begin{array}{c}0.9204 \\
(0.4392)\end{array}$ & $\begin{array}{c}0.9704 \\
(0.4228)\end{array}$ & $\begin{array}{c}1.0119 \\
(0.4845)\end{array}$ & $\begin{array}{c}1.8130 \\
(0.5373)\end{array}$ & $\begin{array}{c}1.9733 \\
(0.6399)\end{array}$ & $\begin{array}{c}1.8591 \\
(0.6276)\end{array}$ & $\begin{array}{c}1.8851 \\
(0.5472)\end{array}$ \\
\hline Input Supplier Suburbanization Index & $\begin{array}{l}-0.0510 \\
(0.2366)\end{array}$ & $\begin{array}{l}-0.2282 \\
(0.2089)\end{array}$ & $\begin{array}{l}-0.1521 \\
(0.2159)\end{array}$ & $\begin{array}{l}-0.4796 \\
(0.4512)\end{array}$ & $\begin{array}{l}-0.3500 \\
(0.4898)\end{array}$ & $\begin{array}{l}-0.4324 \\
(0.5192)\end{array}$ & $\begin{array}{l}-0.3462 \\
(0.4555)\end{array}$ \\
\hline Manufacturing & $\begin{array}{c}0.0477 \\
(0.0240)\end{array}$ & $\begin{array}{l}0.0398 \\
(0.0247)\end{array}$ & $\begin{array}{l}0.0478 \\
(0.0235)\end{array}$ & & & & \\
\hline $\begin{array}{l}\text { Log of average firm size } \\
\text { (workers/plants) }\end{array}$ & $\begin{array}{l}-0.0143 \\
(0.0115)\end{array}$ & $\begin{array}{l}-0.0106 \\
(0.0117)\end{array}$ & $\begin{array}{l}-0.0133 \\
(0.0113)\end{array}$ & $\begin{array}{c}0.0306 \\
(0.0130)\end{array}$ & $\begin{array}{c}0.0409 \\
(0.0144)\end{array}$ & $\begin{array}{c}0.0415 \\
(0.0157)\end{array}$ & $\begin{array}{c}0.0325 \\
(0.0118)\end{array}$ \\
\hline $\begin{array}{l}\text { Percent with } \\
\text { high school degree }\end{array}$ & & $\begin{array}{l}0.1026 \\
(0.1550)\end{array}$ & & & & & \\
\hline $\begin{array}{l}\text { Percent with college } \\
\text { or higher degree }\end{array}$ & & $\begin{array}{l}-0.1771 \\
(0.0983)\end{array}$ & & & & & \\
\hline $\begin{array}{l}\text { Percent of industry workers } \\
\text { using computers at their job }\end{array}$ & & & $\begin{array}{c}-0.000011 \\
(0.00000499)\end{array}$ & & & & \\
\hline $\begin{array}{l}\text { Dollar value } \\
\text { per pound of output }\end{array}$ & & & & $\begin{array}{l}-0.0019 \\
(0.0009)\end{array}$ & & & $\begin{array}{l}-0.0016 \\
(0.0009)\end{array}$ \\
\hline $\begin{array}{l}\text { Share of domestic production } \\
\text { that is exported }\end{array}$ & & & & & $\begin{array}{l}-0.0356 \\
(0.0193)\end{array}$ & & $\begin{array}{l}-0.0279 \\
(0.0200)\end{array}$ \\
\hline $\begin{array}{l}\text { Energy expenditure } \\
\text { per dollar of output }\end{array}$ & & & & & & $\begin{array}{l}-0.0075 \\
(0.0075)\end{array}$ & $\begin{array}{c}0.0072 \\
(0.0180)\end{array}$ \\
\hline $\mathrm{R} 2$ & 0.0625 & 0.1149 & 0.0938 & 0.3884 & 0.3580 & 0.3294 & 0.4003 \\
\hline Number of clusters & 69 & 69 & 65 & 20 & 20 & 20 & 20 \\
\hline Number of observations & 434 & 434 & 416 & 123 & 137 & 137 & 120 \\
\hline
\end{tabular}

Standard errors reported in parentheses. Intercepts calculated but not shown.

Results reported are for regression with correction for correlation in error structure within two-digit SIC codes. 
Table 9 Firm Location and Desire for Suburbanization

Dependent variable:

MSA/SIC log-level slope

specification

\author{
Worker Suburbanization \\ Index \\ Input Supplier \\ Suburbanization Index
}

MSA fixed-effects

SIC fixed-effects

R2

$\mathrm{N}$
0.0370
$(0.001)$
0.0350
$(0.001)$
0.0750
0.0750
$(0.002)$
$(0.001)$

Yes

Yes

Two-digit Three-digit
Share of MSA/SIC Employment Outside the Inner Three Mile Ring

(3)

$\begin{array}{ll}0.2440 & 0.2270 \\ (0.008) & (0.007) \\ & \\ 0.2960 & 0.2990 \\ (0.011) & (0.010)\end{array}$

Yes Yes

Two-digit Three-digit

$14230 \quad 14230$

$0.364 \quad 0.455$

The unit of analysis is the MSA/SIC pair. In specification (1) and (2) the dependent variable is the slope of a MSA/SIC specific regression of log(employment density) on distance.

The mean of this variable is -.033 and its standard deviation is 0.033 .

In specification (3) and (4) the dependent variabe is the share of employment in a

a given MSA/SIC outside of the inner three mile ring.

The mean of this variable is 0.690 and its standard deviation is 0.291 .

The explanatory variables include MSA and SIC fixed effects and the

Worker Suburbanization Index and the Input Supplier Suburbanization Index.

Both of these variables are defined in the text.

Standard errors are presented in parentheses.

The variable "Worker Suburbanization Index" has a mean of 0.57 and a standard deviation of 0.154 .

The variable "Input Supplier Suburbanization Index " has a mean of 0.29 and a standard deviation of 0.21 . 
Dependent variable: Surburban employment growth in sector (see Note for definition)

\begin{tabular}{|c|c|c|c|c|c|}
\hline & All & Service & Manufacturing & |FIRE (finance) & Government \\
\hline 1969 population share & $\begin{array}{c}0.0542 \\
(0.0200)\end{array}$ & $\begin{array}{c}0.0599 \\
(0.0204)\end{array}$ & $\begin{array}{c}0.0881 \\
(0.0260)\end{array}$ & $\begin{array}{c}0.0818 \\
(0.0254)\end{array}$ & $\begin{array}{c}0.0266 \\
(0.0142)\end{array}$ \\
\hline $\begin{array}{l}\mathrm{R} 2 \\
\mathrm{~N}\end{array}$ & $\begin{array}{c}0.0772 \\
322\end{array}$ & $\begin{array}{c}0.0839 \\
318\end{array}$ & $\begin{array}{c}0.1073 \\
322\end{array}$ & $\begin{array}{c}0.1393 \\
320\end{array}$ & $\begin{array}{c}0.0246 \\
322\end{array}$ \\
\hline
\end{tabular}

Using 1969 and 1997 data from the US Bureau of Census REIS CD-ROM, we construct the share of MSA jobs in the suburban counties.

Suburban counties are defined to be those counties that are in the MSA but do not have the largest county population

in the MSA in 1969. The dependent variable in each of these regressions is the first difference of the suburban employment

share between 1969 and 1997 . The explanatory variable is constructed by calculating the share of the MSA's population

who lived in the suburban counties in 1969. Each column reports the regression for a different employment

sector. All regressions include region fixed effects and demographic controls as described in Table Eight.

Robust standard errors are reported in parentheses. Intercepts calculated but not show. 
Table 11 Political Boundary Effects

The Ten MSA Featuring

the Greatest Negative Employment Effects

MSA

center city

border effect

$\begin{array}{ll}\text { San Francisco } & -1.8847 \\ \text { San Jose } & -1.4371 \\ \text { Philadelphia } & -0.4675 \\ \text { Phoenix } & -0.4410 \\ \text { Washington } & -0.4339 \\ \text { Boston } & -0.3567 \\ \text { Chicago } & -0.3354 \\ \text { Springfield } & -0.3161 \\ \text { New Orleans } & -0.2896 \\ \text { Baltimore } & -0.2728\end{array}$

The Ten MSA Featuring

the Greatest Positive Employment Effects

MSA

center city border effect

Toledo

0.9279

Cinncinati $\quad 0.9866$

Birmingham $\quad 1.0058$

Richmond $\quad 1.0712$

Charlotte $\quad 1.1171$

Columbia $\quad 1.2529$

Buffalo $\quad 1.2694$

Atlanta $\quad 1.2702$

Indianapolis $\quad 1.2771$

Louisville $\quad 1.5750$

This table reports the estimate of the center city dummy based on equation (6) in the text The dependent variable is a zip code's log(job density/population density)

Center city is a dummy variable that equals one if the zip code is located in the center city 